\title{
VII. Ergebnisse und ein Ausblick - Memoria als Gabentausch oder: das Ende der antiken Stadt
}

Das spätantike Rom zwischen dem 3. und 5. Jh. war der Schauplatz einer tiefgreifenden kulturellen und urbanistischen Transformation, die das gesellschaftliche Gefüge und das äußere Erscheinungsbild der Stadt nachhaltig veränderte. Fragt man nach der Rolle, die die Heiligenverehrung in diesem Prozess spielte, wird man ihr auf den ersten Blick keine besondere Bedeutung im Sinne eines Faktors zuweisen, der einen grundlegenden Strukturwandel herbeigeführt hätte. Konstantin hatte der Topographie des römischen Heiligen- und Totenkults erstmals ein öffentliches Gesicht verliehen, indem er mehrere Basiliken errichtete, die als monumentale Grablegen und Orte der Totenmemoria dienen sollten. Deren periphere, außerhalb der Stadt befindliche Lage hatte jedoch keine Ausgrenzung aus dem städtischen Raum zur Folge: Indem sie mit dem Kaiserkult eine für die Kommunikation des Kaisers mit seiner Stadt traditionell bedeutsame Funktion übernahmen, waren die konstantinischen Basiliken nicht eine kaiserliche Privatangelegenheit, sondern ein integrativer Bestandteil der Stadt und der städtischen Identität. In ähnlicher Weise blickte auch Damasus, der als erster römischer Bischof eine umfassende und systematische Monumentalisierung der römischen Heiligentopographie betrieb, von der Stadt aus auf die Heiligen, nicht umgekehrt: Damasus' bischöfliches Selbstverständnis unterstellte sich nicht der Macht heiliger Patrone, sondern machte die Heiligen zu Mitgliedern seiner kirchlichen Gemeinde - und deren Existenz war ihrerseits nicht ablösbar von der Stadt und dem städtischen Raum, an den sie symbolisch gekoppelt war. Die „Einbürgerung“ der Heiligen, die Damasus durch ihre Bezeichnung als cives bewerkstelligte, diente nicht einer christlichen Transformation der Stadt, sondern umgekehrt einer symbolischen Ausdehnung der städtischen Grenzen bis in das Suburbium hinein: Als Bürger wurden die Heiligen Teil der - an der Stadt orientierten - ecclesia und verliehen ihr innerhalb der Reichskirche den Glanz, den das alte caput imperii auch nach dem Verlust seiner hauptstädtischen Funktion noch verströmte. Als konkurrierende Bezugspunkte einer alternativen städtischen Identität hat Damasus die Heiligen und ihre außerhalb der Stadt liegenden „Wohnstätten“ hingegen nicht verstanden.

Dies änderte sich unmittelbar nach Damasus' Tod, als die auf ihn folgende Generation in theodosianischer Zeit die periphere Lage der 
suburbanen Heiligentopographie zum Anlass nahm, um sie in einem paradoxen diskursiven Spiel mit der Inversion von Zentrum und Peripherie zum räumlichen Bezugspunkt einer neuen, christlichen Stadt Rom zu machen: Damasus war durch die romanisierende Sprache seiner Epigramme die nun ihrerseits Ansatzpunkte für eine Christianisierung der kulturellen Modelle bot, derer sich Damasus bedient hatte - zum Wegbereiter einer Entwicklung geworden, an der er selbst nicht Teil gehabt hatte. Auch unter diesen gewandelten Voraussetzungen blieben die Heiligen jedoch auf die Stadt als kulturelle Einheit bezogen. Sie fungierten als Patrone Roms, nicht einzelner lokaler Zentren. Dafür, dass sich aus dem Schutz individueller Heiliger wirkungsvolle Ansätze für Formen kollektiver Identitätsstiftung jenseits einer städtischen Identität entwickelten, fehlen zunächst die Anhaltspunkte. Erst im Laufe des 5. Jh. verdichten sich die Hinweise auf eine derartige Entwicklung: Die Stationsliturgie und die Heiligenlegenden machen deutlich, dass die Kirchen und Heiligenpatrozinien in stärkerem Maße als zuvor Kristallisationspunkte innerhalb eines polyzentrischen Raums bildeten. Die damit verbundene Schwächung des städtischen Zusammenhangs ist jedoch nicht ursächlich aus der Verehrung der Heiligen zu erklären: Sie erscheint eher als Reflex und Nebenerscheinung denn als eine treibende historische Kraft des urbanistischen Wandels. Den entscheidenden Anstoß zur Nuklearisierung des städtischen Raums lieferten andere Faktoren - der demographische Niedergang und die damit einhergehende Veränderung des Stadtbildes, die einer entsprechenden Tendenz auch im Bereich der christlichen Sakraltopographie Roms Vorschub leisteten.

Vordergründig scheint die Heiligenverehrung dementsprechend einen nur bescheidenen Beitrag zur Transformation Roms in der Spätantike geleistet zu haben. Gegen eine derartige Einschätzung soll im folgenden die Position vertreten werden, dass sich im spätantiken Rom erhebliche strukturelle Umgestaltungen in der Formierung kollektiver Identitäten und des sozialen Zusammenhalts von Gruppen vollzogen, die auf lange Sicht zu einer Auflösung der Stadt in ihrem sozial-gesellschaftlichen und urbanistischen Sinne führten. Der Toten- und Heiligenmemoria kommt für diesen Prozess insofern eine besondere Bedeutung zu, als in ihr die spezifischen Ausprägungen einer christlichen Memorialkultur sichtbar werden, die ein Transformationspotential von erheblicher Reichweite in sich barg. Um dies zu zeigen, sollen im folgenden - ausgehend von den Ergebnissen der Teilkapitel - nochmals diejenigen Momente rekapituliert werden, die deutlich machen, dass unter den Bedingungen einer christlichen Memorialkultur Wandlungsprozesse in Gang gesetzt wurden, die auf lange Sicht eine Transformation der spätantiken Stadt bewirkten.

Diese Art der Schlussbetrachtung bietet dementsprechend nicht eine primär summarische Wiedergabe des bereits in den Zusammenfassungen zu 
den einzelnen Teilkapiteln Erarbeiteten, sondern zielt in Form einer conclusio darauf $\mathrm{ab}$, das strukturelle Veränderungspotential herauszuarbeiten, das durch die Heiligenverehrung und eine spezifisch christliche Prägung des Totengedenkens während der Spätantike für die Konstruktion von kollektiven Identitäten gegeben war. In einem zweiten Schritt sollen diese Veränderungen zum Anlass genommen werden, das Toten- und Heiligengedenken in den weiteren Kontext einer christlichen Memorialkultur einzuordnen sowie deren spezifische Voraussetzungen und Ausformungen zu verdeutlichen, die sich fundamental von denen ihres historischen Umfeldes unterschieden und langfristig zu einer Auflösung der antiken Stadt und des städtischen Raums führten.

\section{1. Ergebnisse}

Die Refrigerien, die während der zweiten Hälfte des 3. Jh. für Petrus und Paulus in der Triklia unter der späteren Basilika von S. Sebastiano gefeiert wurden, machen exemplarisch die spezifischen Voraussetzungen deutlich, unter denen im Christentum kollektive Identitäten durch die Erinnerung an die Toten begründet wurden. Obwohl die Refrigerienmähler, die die Besucher der Triklia im Gedenken an Petrus und Paulus feierten, in ihrer äußeren Form den Mahlfeiern entsprachen, die in der Kaiserzeit von Kollegien für ihre verstorbenen Mitglieder abgehalten wurden, liegt den Mählern unter S. Sebastiano eine andere Vorstellung von den Beziehungen zugrunde, in die die Lebenden durch diese Feiern zu den von ihnen geehrten Toten traten. Im traditionellen römischen Totenkult imaginierte man zwar die Gegenwart des Verstorbenen, stellte jedoch keine echte Mahlgemeinschaft mit ihm her: Als Toter verblieb er außerhalb der Gemeinschaft der Lebenden, die sich an seinem Grab zum Mahl versammelte. Die kollektive Identität der Lebenden formierte sich zum einen - rituell - durch eine Abgrenzung der Hinterbliebenen, die sich nach der Separierung von dem verstorbenen Mitglied einer Gruppe wieder als Gemeinschaft der (Über-)Lebenden zusammenfanden. Zum anderen wurde im Gedenken der Tote retrospektiv in der Funktion vergegenwärtigt, die er zu Lebzeiten in seinem Verhältnis zu denjenigen eingenommen hatte, die sich zu seiner Kommemoration versammelten: Auch noch im Tod gab der Verstorbene den Lebenden Veranlassung, zum Mahl zusammenzukommen und sich damit eines sozialen Handlungszusammenhangs zu erinnern, der zu Lebzeiten des Toten bestanden hatte. Besonders deutlich wird diese Funktion des paganen Totenmahls dort, wo die Mahlfeiern auf Stiftungen oder auf die Beitragszahlungen zurückgingen, die die Mitglieder eines Kollegiums geleistet hatten: Der Sinn dieser Investitionen bestand nicht darin, eine rituelle Versorgung des Toten mit den sacra 
sicherzustellen, sondern darin, auch nach dem Tod als Euerget gegenüber einer Gemeinschaft tätig zu bleiben und in dieser Eigenschaft von ihr kommemoriert zu werden. ${ }^{1}$ Die Handlungszusammenhänge zwischen den Lebenden und den Toten, die im Gedenken wirksam wurden, waren somit auf das Leben zentriert: Sie hielten Verbindungen lebendig, die zu Lebzeiten begründet worden waren, und bildeten innerweltliche Verhältnisse ab.

Grundlegend anders gestaltete sich die Relation der Lebenden zu den Toten nach christlichen Vorstellungen, wie sie in der frühchristlichen Sepulkralepigraphik und in den Refrigerien für die Märtyrer zutage traten: Das soziale Leben der christlichen Gemeinden strukturierende Schlüsselbegriffe wie pax, refrigerium und caritas behielten auch in der Relation zu den Toten eine bestimmende Bedeutung, indem sie Lebende und Tote in einen Handlungszusammenhang brachten, der über die Grenze des Todes hinweg Bestand hatte. Die Heiligen blieben, wie die Toten insgesamt, einbezogen in ein semantisches Bezugssystem von sozialethischen Handlungsbegriffen, die das Leben der Gemeinden regelten und auch auf die Toten ausgedehnt wurden. Das christliche Totengedenken war damit kein rein retrospektives Erinnern an das, was der Tote einst zu seinen Lebzeiten gewesen war, sondern Ausdruck der Vorstellung, mit den Toten auch in der Gegenwart in einem reziproken Handlungszusammenhang verbunden zu sein. Wirksam wurden diese Interaktionsbeziehungen im Gebet, das die Toten für die Lebenden aus Dank für die von ihnen dargebrachten Gaben der Erquickung übernahmen.

Dieser Austausch von Gabe und Fürbitte setzte prinzipiell Interaktionsbeziehungen fort, die auch die Gemeinschaftsbildung unter den Lebenden strukturiert hatten: Bereits zu Lebzeiten der Märtyrer hatten diese in einem regen Austausch mit Besuchern gestanden, die ihnen im Gefängnis durch Mähler, durch den Trost ihrer Besuche und durch ihren Zuspruch ein refrigerium bereiteten. Das bevorstehende Martyrium schuf ein Feld intensiver reziproker Handlungsbeziehungen, durch die die Märtyrer und ihre Besucher wechselseitig füreinander tätig wurden. Die Confessoren, denen schon vor der Vollendung ihres Martyriums eine besondere Nähe zu Gott und eine erhöhte Fähigkeit zur Interzession zugeschrieben wurden, machten davon Gebrauch, indem sie mit den lapsi, die um Vergebung für ihren Glaubensabfall baten, Gemeinschaft hielten und ihnen Friedensbriefe ausstellten, die ihre Schuld als getilgt auswiesen. Umgekehrt waren aber auch die Confessoren auf die Fürsorge und das Fürbittgebet ihrer Besucher angewiesen, um im bevorstehenden Kampf nicht zu versagen und die Bereitschaft zum Martyrium bis zu dessen Vollendung aufrechtzuerhalten. Beides zusammengenommen schuf ein durch wechselseitige Verdemütigung charakterisiertes Handlungsfeld, in dem die Reziprozität des gegenseitigen Gedenkens zwar

Vgl. dazu auch exemplarisch die u., S. 513f. besprochenen Stiftungen des Cominius Abascantus. 
durchaus ritualisierte Züge annahm, sich aber aufgrund der offenen, rituell nicht kontrollierbaren Situation - der Ausgang des Martyriums war ungewiss - nicht auf einen Austausch performativer Gesten reduzieren lässt.

Dieser reziproke Handlungszusammenhang blieb nach christlicher Auffassung über die Grenze des Todes hinweg wirksam, barg damit jedoch zugleich auch das Potential in sich, innerweltliche Handlungsbeziehungen zu schwächen. Bereits die Vorstellung, dass die Heiligen als Interzessoren über eine besondere Nähe zu Gott verfügten, bedeutete einen Bruch mit dem in der Kirchenbuße verwirklichten Prinzip, Sündenvergebung und Heil innerhalb der Gemeindestrukturen zu suchen. Stattdessen wandte man sich an Fürsprecher, denen man bereits in der Vorbereitung auf das Martyrium eine das normale menschliche $\mathrm{Maß}$ übersteigende Gottesnähe zuerkannte. $\mathrm{Zu}$ Lebzeiten der Heiligen erhielt diese in den interzessorischen Fähigkeiten der Heiligen angelegte Tendenz zur Distanzierung und Entrückung aus menschlichen Handlungsbeziehungen durch die Betonung der ihrerseits für sie vorgenommenen Fürbitte ein wirksames Gegengewicht, das die Ausbildung einer hierarchischen Relation zwischen den Märtyrern und den „normalen“ Christen verhinderte. Die Heiligen selbst hoben ihre Einbindung in einen menschlichen und innerweltlichen Handlungszusammenhang durch Gesten der Verdemütigung hervor. Dieses Korrektiv fiel unter der Voraussetzung, dass sich das Heiligengedenken zum Totengedenken wandelte, weg. Die toten Heiligen wurden nun zu einseitigen Empfängern von vota, die ihren Rang als Mittlergestalten zwischen der göttlichen und der menschlichen Welt betonten und die Heiligen aus der Handlungsgemeinschaft mit den Gläubigen deutlich heraushoben. Die als ein Spezifikum der christlichen Memorialkultur anzusehende Gemeinschaft zwischen Lebenden und Toten entfaltete auf diese Weise eine paradoxe Wirkung. Einerseits war die Vorstellung von einer umfassenden menschlichen Handlungsgemeinschaft eine Grundvoraussetzung für die Überzeugung, dass die Heiligen auch nach dem Tod aufgrund ihrer menschlichen communio mit den übrigen Mitchristen verbunden blieben und sich für sie einsetzten. Andererseits war diese Handlungsgemeinschaft zwischen Märtyrern und „normalen“ Christen als solche nicht sozial erfahrbar: Anders als in der Kommunikation mit den lebenden Heiligen, in der sozialethische Prinzipien der innerweltlichen Gemeinschaftsstiftung nachdrücklich betont worden waren, entwickelten sich die toten Heiligen mehr und mehr zu übermenschlichen Bezugspunkten von Handlungsbeziehungen, die einen ursprünglich innerweltlichen Handlungsrahmen transzendierten.

Mit Konstantin gewann der christliche Totenkult, der bis dahin eine Angelegenheit der christlichen Gemeinde und kleiner, in ihren Dimensionen den traditionellen kaiserzeitlichen Kollegien vergleichbarer Gruppen gewesen war, eine neue Dimension. An der via Labicana errichtete der Kaiser einen Toten- 
kultkomplex aus einer coemeterialen Basilika und einem kaiserlichen Mausoleum, dessen spätere Bezeichnung als Basilika der Heiligen Petrus und Marcellinus die ursprüngliche Funktion, die diese Anlage erfüllen sollte, verdeckt: Die beiden Heiligen, deren Grablege in der Katakombe unterhalb der Basilika keine Verbindung zu dem oberirdischen Kultkomplex hatte, und die in der hagiographischen Tradition des 4. Jh. keine erkennbare Rolle spielen, sind vermutlich erst durch den Bau der Basilika zu allgemeiner Bekanntheit gelangt. Der Grund für die Errichtung der Umgangsbasilika und des kaiserlichen Mausoleums, das vermutlich ursprünglich als Konstantins Grablege geplant gewesen war, bestand nicht in der Monumentalisierung eines obskuren Märtyrergedenkens an der via Labicana, sondern in der räumlichen Beziehung zum Sessorium, das Konstantin auf der Grundlage mehrerer älterer Kaiserresidenzen zu einem großen Palastkomplex ausbaute. Der Kaiser etablierte damit im Südosten der Stadt ein kaiserliches Machtzentrum, das er in eine enge Verbindung mit einer Reihe von christlichen Kultbauten brachte: der Palastkirche S. Croce innerhalb des Sessoriums, der bischöflichen Lateranbasilika in der Nähe des Palastes und dem christlichen Totenkultkomplex an der via Labicana.

Die Ausstattung des dortigen Mausoleums mit liturgischen Gerätschaften macht deutlich, dass es dem Kaiser nicht darum ging, in der Nähe verehrter Heiliger bestattet zu werden und an herausragender Stelle, ad sanctos, an einem Kult für diese Heiligen zu partizipieren. Bei aller Unsicherheit über die kultischen Praktiken, die in der Basilika und in dem angrenzenden Mausoleum begangen wurden, ist unverkennbar, dass der Kaiser an der via Labicana einen christlichen Totenkult erstrebte, der unmittelbar seiner eigenen Person galt und ihn damit in den Rang eines Heiligen erhob. Kulturelle Vermittlungsprobleme ergaben sich daraus weder für Konstantin noch für die Christen, die sich mit diesem außergewöhnlichen Ansinnen des Kaisers konfrontiert sahen. Eine ausgeprägte, in der eucharistischen Liturgie ebenso wie im nichteucharistischen christlichen Totengedenken begegnende Oblationspraxis für die Toten war Konstantin in ihren äußeren Formen auch aus dem paganen Totenkult vertraut. Umgekehrt bereitete es aus christlicher Perspektive keine Probleme, dem Kaiser formal den von ihm erstrebten Status eines Heiligen einzuräumen - auch wenn man ihn nicht mit den Märtyrern auf eine Stufe stellen wollte -, da das Heiligengedenken zumindest unter liturgischen Gesichtspunkten im 4. Jh. nichts anderes als ein besonderes Totengedenken war, man also nicht qu den Heiligen, sondern für sie betete.

Für die Frage, welche Rolle Konstantin der christlichen Gemeinde mit Blick auf die städtische Identität der urbs Roma zuwies, ist diese Interpretation von entscheidender Bedeutung. Konstantins Errichtung einer christlichen Kaiserkultstätte an der via Labicana verdeutlicht, dass traditionelle Deutungen der konstantinischen Baupolitik entlang einer Linie von „paganem Zentrum“ 
versus „christliche Peripherie“ oder „städtischer Öffentlichkeit“ versus „privates kaiserliches Handeln" an der Sache vorbeigehen: Der Kaiser verlagerte mit dem Kaiserkult ein wesentliches Moment kollektiver städtischer Identitätsstiftung in einen christlichen Kommunikationsraum. Da er beabsichtigte, seine sterblichen Überreste zum Zentrum des Kaiserkults zu machen, zog dies notwendigerweise eine räumliche Verlagerung in die Außenbereiche jenseits der städtischen Mauern mit sich, bedeutete jedoch keine Ausgrenzung der christlichen Kultgemeinschaft aus dem städtischen Raum und der städtischen Identität. Vielmehr konstituierte die Person des Kaisers eine umfassende städtische Öffentlichkeit, die durch unterschiedliche Gruppen gebildet wurde, mit denen Konstantin kommunizierte. Auch wenn die konstantinischen Kultbauten räumlich außerhalb der städtischen Mauern Roms lagen, waren sie ein zentraler Ort einer auf die Stadt bezogenen Kommunikation und Öffentlichkeitsbildung, keine periphere oder „private“ Angelegenheit des Kaisers.

Konstantin kommunizierte nach dieser Deutung sowohl im Zentrum Roms als auch in der suburbanen Sakraltopographie für die Stadt Rom identitätsrelevante Themen gegenüber einer städtischen Öffentlichkeit, die sich aus unterschiedlichen Akzeptanzgruppen zusammensetzte. Im Zentrum der Stadt nutzte Konstantin die maxentischen Bauten im Bereich der via sacra und das Zeremoniell des kaiserlichen adventus, um der Befreiung der Stadt Rom von der „Tyrannis“ des Maxentius symbolischen Ausdruck zu verleihen. Diese Inszenierung der Befreiung verlangte eine Kommunikation mit dem populus romanus, jedoch vor allem mit der senatorischen Oberschicht, der in der diskursiven Konstruktion des Tyrannen traditionell die Rolle zufiel, in besonderer Weise unter der Herrscherwillkür zu leiden. Eine Beteiligung der Christen war in diesem Zusammenhang hingegen nicht erforderlich: Selbst christliche Autoren gaben der „Tyrannis“ des Maxentius nicht den Charakter einer Christenverfolgung, sondern zeichneten sie im Sinne der traditionellen politischen Semantik als tiefgreifende Störung des Verhältnisses des Herrschers zur senatorischen Oberschicht. Anders sah die Situation im Kaiserkult aus. In diesem Bereich städtischer Kommunikation mit dem Kaiser wuchs der christlichen Gemeinde eine entscheidende Rolle als Adressat und Akteur zu. Der christliche Toten- und Heiligenkult bot ein geeignetes kulturelles Modell, um die von Konstantin angestrebte Verbindung von divus- und Totenkult zwei Bereichen, die in Rom traditionell voneinander getrennt waren - unter den Vorzeichen einer neuen Form des Kaiserkults herzustellen.

Konstantin führte damit nicht nur den römischen Kaiserkult in christlichem Gewande weiter, er formte ihn auch um: Der divus und der tote Kaiser hatten im römischen Kaiserkult traditionell getrennte Register von Göttlichkeit gebildet, die unterschiedliche Formen der kultischen Verehrung verlangten und nicht ineinander integrierbar waren. Konstantin bewerk- 
stelligte eine derartige Symbiose im christlichen Totenkult und stellte damit den römischen Kaiserkult auf eine neue Grundlage. Konstantins Motive für diese Umformung entsprangen weniger einer Konzession an die christliche Religion, aus deren Perspektive eine Weiterführung der traditionellen Divinisierung des Kaisers Probleme hätte bereiten können. Neben der Ausschaltung potentieller Konflikte um eine Erhebung des Kaisers zum Gott war Konstantins Entscheidung eine gezielte Option, geboren aus der Erkenntnis, dass der christliche Totenkult ein geeignetes kulturelles Modell für eine Integration von divus- und Totenkult bot, die sich bereits in tetrarchischer Zeit abgezeichnet hatte. Das seit dem 3. Jh. nachweisbare Selbstverständnis der römischen Kaiser, als gottbeauftragt zu handeln und in ihrer Begründung von Autorität nicht mehr von menschlicher Zuschreibung und der Anerkennung ihrer Leistung abhängig zu sein, hatte auch Auswirkungen auf den Status des toten Herrschers. Die Erhebung zum divus und die Konsekration des Kaisers waren traditionell die letzten Akte eines Handlungszusammenhangs, in dem Leistungen der Kaiser durch die menschliche Zuweisung von Ehre beantwortet wurden. Indem - erkennbar seit tetrarchischer Zeit - die Grablegen und die sterblichen Überreste des Kaisers zum Fokus seiner Verehrung als Gott avancierten, wurden diese Handlungszusammenhänge unterlaufen. Der Kaiser erhob dadurch den Anspruch auf einen übermenschlichen Status, der nicht auf der Einrichtung eines Kultes für den zum divus erhobenen Kaiser beruhte. Das Numinose war damit keine Angelegenheit menschlicher Zuschreibung mehr, sondern vielmehr eine davon unabhängige Qualität, eine Eigenschaft, die dem Kaiser zu Lebzeiten wie in seinem Tod eignete: Er war - verkörpert auch in seinen sterblichen Überresten - mehr als ein Mensch. Der christliche Toten- und Heiligenkult bot Konstantin eine Möglichkeit, diese Lösung des römischen Kaisers aus den menschlichen Handlungsbeziehungen überzeugend zu bewerkstelligen, da er eine Verbindung von Toten- und Götterkult darstellte, für die es in der paganen Tradition kein kulturelles Modell gab. Konstantin betrieb auf diese Weise nicht einfach nur eine Christianisierung des traditionellen Herrscherkults, sondern leistete einem grundlegenden Wandel in der Konzeptualisierung der Handlungsbeziehungen zwischen dem toten Kaiser und der Bevölkerung Vorschub.

In den Auseinandersetzungen, die im 4. und frühen 5. Jh. um den römischen Bischofsstuhl geführt wurden, spielte die Heiligenerinnerung keine zentrale Rolle für die Legitimierung episkopaler Führungsansprüche. Für die Konkurrenten um das Bischofsamt war der Nachweis eines funktionierenden Handlungszusammenhangs mit den lebenden Gemeindemitgliedern wichtiger als eine intensive Nahbeziehung zu den besonderen Toten. Mehr als das: Deren Lokalisierung in den Coemeterien außerhalb der Stadtmauern machte die 
Heiligentopographie geradezu zu einem ungeeigneten Schauplatz, um das kulturelle Modell zu verkörpern, das für einen rechtmäßigen Anwärter auf den römischen Bischofsthron maßgeblich war: das des Hirten im Kreis seiner Herde. Um als pastor gregis aufzutreten, musste derjenige, der den Anspruch auf die römische cathedra erhob, sich dort befinden, wo auch die bischöfliche Herde war, und das war der städtische Raum innerbalb der Stadtmauern. Die römische Bischofscathedra hatte ihren symbolischen Ort nicht am Petrusgrab am Vatikan, sondern in der Stadt.

Diese Regel galt nicht nur bei Doppelwahlen, die akute Auseinandersetzungen um die Besetzung des römischen Bischofsstuhls hervorriefen, sondern auch bei Schismen, die über längere Zeit hinweg bestanden und zur Verfestigung separater Sondergemeinden führten. Auch für sie war die räumliche Präsenz innerhalb der Stadt von zentraler symbolischer Bedeutung; die Heiligentopographie in den Coemeterien des Suburbiums bot schismatischen Gruppen und Sondergemeinden allenfalls die Möglichkeit, sich weiterhin in einem Bereich zu versammeln, der aufgrund seiner peripheren Lage und der Besitzverhältnisse vom Bischof der katholischen Gemeinde nur schwer zu kontrollieren war. Die Heiligengräber konnten auf diese Weise zwar durchaus eine Rolle für die Formierung schismatischer Gruppen bilden. Ihre Bedeutung lag jedoch primär darin begründet, dass sie ein Rückzugsgebiet bildeten; ein identitätsstiftendes Moment kam der besondere Nähe zu einzelnen Heiligen - die apostolischen Gemeindegründer Petrus und Paulus mit einbegriffen - nicht zu.

Diese Einschränkung war allerdings nur dort wirksam, wo die römische ecclesia in ihrer lokalen Dimension zum Gegenstand von Auseinandersetzungen wurde. Dadurch, dass die römische Bischofscathedra jedoch zugleich die cathedra Petri und damit ein universalkirchliches Symbol war, bildeten sie und die römische Gemeinde zugleich Bezugspunkte von Diskursen, die außerhalb Roms um die Identität der römischen Gemeinde geführt wurden. Aus dieser universalkirchlichen Perspektive kam den apostolischen Grablegen eine identitätsstiftende Bedeutung zu, die sie für die symbolische Konstituierung der römischen ecclesia in ihrer lokalen Dimension nicht hatten: Wo es, wie auf dem Konzil von Serdika oder im nordafrikanischen Donatismusstreit, zu Auseinandersetzungen um die Orthodoxie kam, wurde die Bedeutung der apostolischen Grablegen als Bezugspunkte für die katholische ecclesia nachdrücklich hervorgehoben. Die Differenzierung zwischen lokalen und universalkirchlich ausgerichteten Identitätsdiskursen führte dazu, dass die Verbindung zwischen Räumen und kollektiver Identitätsstiftung unterschiedlich akzentuiert wurde: Die cathedra Petri hatte ihren symbolischen Ort an den Grablegen der Apostelfürsten vor den Toren Roms, die römische Bischofscathedra hingegen in der Stadt. 
Die begrenzte Bedeutung der Heiligengräber für die lokale Begründung der bischöflichen Autorität wird - scheinbar paradox - auch durch die Heiligenepigramme bestätigt, mit denen Damasus flächendeckend den römischen Erinnerungsraum vor den Mauern der Stadt monumentalisierte, um auf diese Weise seine angefochtene Stellung als Bischof der römischen Gemeinde zu stärken. Damasus machte sich nicht zum Klienten der Heiligen, um an der Autorität zu partizipieren, die diese als mächtige Patrone und Interzessoren vermittelten. Seine Perspektive auch auf die Heiligen blieb bestimmt vom Leitbild des pastor gregis und dem kulturellen Modell des Bischofs innerhalb seiner Gemeinde, das für die Begründung bischöflicher Autorität von zentraler Bedeutung war. Damasus, der die Heiligen zu cives romani erklärte und in seiner betont gleichförmigen Gestaltung der Märtyrergrablegen und der Epigramme auf die Hervorhebung individueller Züge verzichtete, unterstellte sich nicht der Hilfe und dem Schutz einzelner Patrone, sondern entwarf ein gezieltes Bild von den römischen Märtyrern als einer Gruppe, die er in die von ihm geleitete römische Gemeinde integrierte. Obwohl Damasus die Fürsprache und die interzessorischen Fähigkeiten der Märtyrer thematisierte, nahm er in den Epigrammen nicht die Haltung desjenigen ein, der sich aus Dank für die von ihnen empfangene Hilfe an sie wandte: Damasus kommentierte, belehrte und redete über die Heiligen - vorzugsweise, indem er Konflikte innerhalb der römischen Gemeinde thematisierte, die zur Zeit der Märtyrer bestanden hatten, und die Rolle hervorhob, die die Heiligen als Friedensstifter zu deren Beilegung gespielt hatten. Gleichzeitig stilisierte sich Damasus zum Übermittler einer mündlich tradierten Erinnerung (fama, audita) an die Heiligen und stellte auf diese Weise zwischen der römischen Gemeinde seiner Gegenwart sowie den Märtyrern als den herausragenden Glaubenszeugen und dem „Ruhm der römischen Gemeinde“ aus der Zeit der Verfolgungen eine enge Verbindung her: Die von Damasus artikulierte Vorstellung eines lokalen, durch mündliche Überlieferung weitergegebenen Wissens band die Märtyrer in eine zeitübergreifende Identitätskonstruktion ein, die sowohl die Heiligen als auch die römische Gemeinde der Gegenwart, in der das Wissens von den Glaubenszeugen der Vergangenheit tradiert wurde und fortlebte, umfasste.

Damasus bemühte die Märtyrer demnach nicht als Mittler zwischen Himmel und Erde, sondern schlug einen umgekehrten Weg ein: Die damasianischen Märtyrer vermittelten keine von Gott abgeleitete Autorität, sondern wurden zu einem Teil der römischen Gemeinde, an deren Spitze der Bischof stand. Legitimierend waren damit auch weiterhin die innerweltlichen Handlungsbeziehungen, die der Bischof zu den Lebenden und zur Gemeinde unterhielt. Diese von Damasus propagierte Haltung und der historisierende modus memorandi, der die retrospektive Erinnerung an die Heiligen, nicht ihre patronale praesentia in den Vordergrund stellte, wurden freilich bereits zu 
Damasus' Lebzeiten obsolet: Sein bischöflicher Amtskollege Ambrosius v. Mailand propagierte ein Bild der Heiligen, das weniger ihre Eigenschaft als exemplarische Blutzeugen der Vergangenheit als vielmehr ihre Macht und helfende Fürsprache in der Gegenwart zum Inhalt des Gedenkens an sie machte. Diesem patronalen Modus des Heiligengedenkens, dessen Genese auch dadurch bedingt war, dass Ambrosius einer Generation angehörte, die im Unterschied zu Damasus - keine biographische Verbindung zur Verfolgungszeit mehr hatte, gehörte die Zukunft: Die Vorstellung von den heiligen Patronen erfuhr seit dem ausgehenden 4. Jh. im lateinischen Westen eine rasche Verbreitung und wurde von einzelnen Bischöfen in dieser Zeit nicht mehr nur auf die christlichen Gemeinden bezogen, sondern auch auf die Städte übertragen. Die heiligen Patrone entwickelten sich damit zu Bezugspunkten von städtischen Identitätsdiskursen, die das bis in die theodosianische Zeit hinein vorherrschende Konzept der Stadt als eines neutralen, nicht religiös qualifizierten Bereichs der antiken Kultur infrage stellten: Sie symbolisierten eine neue, christliche Stadt.

Seit dem ausgehenden 4. Jh. ist diese Entwicklung auch für Rom nachweisbar. Obwohl entsprechende Selbstaussagen römischer Bischöfe aus dieser Zeit nicht überliefert sind, machen die Äußerungen unterschiedlicher christlicher Autoren übereinstimmend deutlich, dass die Heiligengräber und insbesondere die petrinische Grablege am Vatikan als symbolische Zentren einer christlichen städtischen Identität fungierten. Ihre Randlage im Suburbium außerhalb der städtischen Mauern verlieh der römischen Heiligentopographie eine besondere Wirksamkeit für die diskursive Christianisierung der urbs: In der Gegenüberstellung von Zentrum und Peripherie ließ sich der Identitätswandel Roms von einer paganen zu einer christlichen Stadt nachdrücklich versinnbildlichen. Damasus hatte diesem Deutungsmuster nicht nur durch seinen systematischen Ausbau der Heiligentopographie, der dem Suburbium einen dezidiert funeralen Charakter verlieh und einer Abgrenzung zwischen der Stadt und dem Suburbium schärfere Konturen gab, Vorschub geleistet. Vor allem hatte er die Heiligen mit traditionellen kulturellen Modellen städtischer Identitätsstiftung verbunden, um auf diese Weise das Selbstverständnis des caput mundi und die Sprache seiner Eliten für die Autoritätsansprüche der römischen ecclesia innerhalb der Universalkirche verfügbar zu machen. Unter den gewandelten historischen Voraussetzungen einer neuen Zeit bildete diese romanisierende Aneignung die Grundlage dafür, die kulturellen Modelle, derer sich Damasus bedient hatte, nun umgekehrt zu christianisieren: Aus den Heiligen als den cives romani innerhalb der Universalkirche wurden die Bürger einer neuen Stadt.

In derselben Zeit, in der die periphere Heiligentopographie vor den Toren Roms zum symbolischen Bezugspunkt einer neuen städtischen Identität 
wurde, begannen auswärtige Heilige nichtrömischer Provenienz auch in den städtischen Raum einzuwandern. Träger dieser Entwicklung waren Angehörige der römischen Aristokratie, die in der Zeit zwischen dem letzten Drittel des 4. und dem ersten Drittel des 5. Jh. einen maßgeblichen Beitrag zur Ausgestaltung der christlichen Sakraltopographie Roms leisteten, indem sie die Gründung von Titelkirchen veranlassten, die nicht selten in Wohnanlagen dieser aristokratischen Stifter eingerichtet wurden. Eine systematische Überprüfung der archäologischen, kalendarischen und hagiographischen Überlieferung zu den römischen Titelkirchen gibt Anlass dazu, die gängige Forschungsmeinung, das Gros der tituli habe erst seit dem 6. Jh. über Heiligenpatrozinien verfügt, zu revidieren. Vielmehr deutet der Befund in zahlreichen Fällen darauf hin, dass die Titelkirchen bereits zum Zeitpunkt ihrer Gründung mit Heiligenpatrozinien ausgestattet wurden. Auf welche Weise die Reliquien, mit deren Translation und Rekondierung die Einrichtung eines Patroziniums verbunden war, ihren Weg in die römischen Kirchengebäude fanden, lässt sich der Quellenlage in den meisten Fällen nicht entnehmen. Es kann jedoch als sicher gelten, dass die Überführung von Reliquien im wesentlichen auf das Konto derselben Schicht ging, die auch die Einrichtung der Kirchen selbst veranlasste. Auch die stadtrömische Elite partizipierte damit an einer Entwicklung, die für andere Aristokraten um die Wende vom 4. zum 5. Jh., wie Paulinus v. Nola, Sulpicius Severus und Melania d. Ä., die Reliquien als wertvolle und statusadäquate Gaben zur Pflege von Freundschaftsbeziehungen nutzten, umfassend dokumentiert ist.

In dieser Zeit hatten die aristokratischen domus Roms noch nichts von ihrer traditionellen Relevanz als Zentren der gesellschaftlichen und politischen Kommunikation eingebüßt. Mit dem Wiedererstarken einer unter Konstantin reorganisierten Senatsaristokratie kam es innerhalb der römischen Oberschicht verstärkt zu Faktionsbildungen und Parteikämpfen, die die gesamte zweite Hälfte des 4. Jh. prägten, und in deren Verlauf aristokratische amicitia- und Patronagebeziehungen an gesellschaftsstrukturierender Bedeutung gewannen. Die Beteiligung der senatorischen Elite an Reliquientranslationen und der Überführung von Heiligenkulten in die städtischen Titelkirchen wirft damit die Frage auf, ob unter diesen politischen Rahmenbedingungen der Besitz von Reliquien gesteigertes Prestige und soziales Ansehen vermittelte, und inwieweit Heiligenkulte eine identitätsstiftende Bedeutung für Formen der sozialen Gemeinschaftsbildung erlangten, die auf Patronage- und Freundschaftsbeziehungen beruhten.

Die Antwort auf diese Frage ist ambivalent, macht jedoch deutlich, dass der Heiligenkult nicht ohne weiteres in die traditionellen Mechanismen aristokratischer Autoritätsbildung integrierbar war. Zwar spielten die sterblichen Überreste der Heiligen durchaus eine wichtige Rolle als Kommunikationsmittel einer christlichen Elite, zu deren Integration und 
interner Statusdifferenzierung die Weitergabe und Vermittlung von Reliquien einen wesentlichen Beitrag leisteten. Trotz dieser Verwendung von Reliquien als Gaben, die Sozialbeziehungen im Stile traditioneller amicitia- und Patronageverhältnisse begründeten, war der Heiligenkult im spätantiken Rom jedoch offenkundig kein Feld, auf dem Patronagebeziehungen wirksam wurden. Anders als zeitgleich in Konstantinopel, wo städtische Märtyrerschreine und an ihnen lebende Mönche ein vom Bischof kaum zu kontrollierendes Potential für die Versorgung und Patronage durch vermögende Laien eröffneten, scheint es in Rom vergleichbare Möglichkeiten nicht gegeben zu haben: Die Existenz von städtischen Oratorien mit Heiligenkulten ist in Rom praktisch nicht nachweisbar, und die Klöster, die erstmals um die Mitte des 5. Jh. an den Basiliken des römischen Suburbiums begegnen, waren fest in die amtskirchliche Organisation eingebunden.

Noch bemerkenswerter ist der Umstand, dass auch innerhalb der aristokratischen Haushalte die Heiligen und ihre Reliquien offenbar nicht dazu dienten, den Status und das soziale Prestige des Hausbesitzers gegenüber der Öffentlichkeit seiner Freunde und Klienten herauszustellen. Hausoratorien wie das unter der späteren Titelkirche der Heiligen Johannes und Paulus am clivus Scauri verdeutlichen exemplarisch, dass die Heiligen in der öffentlichkeitsorientierten räumlichen Struktur der domus Bezugspunkte des Rückzugs und des individuellen Gebets bildeten. In vergleichbarer Weise thematisieren auch asketisch gefärbte literarische Zeugnisse des ausgehenden 4. Jh., dass die Heiligenerinnerung innerhalb der domus eine Funktion des privaten Raums akzentuierte, die quer zur traditionellen Bedeutung des römischen Hauses als gesellschaftlichem und politischem Kommunikationszentrum lag: Private Oratorien boten die Möglichkeit, die Öffentlichkeit der Märtyrerkultstätten zu umgehen und das asketische Postulat des Rückzugs aus der Welt mit einer ausgeprägten Heiligenfrömmigkeit zu verbinden.

Wie weit diese Haltung für Formen der Heiligenverehrung im privaten Raum der spätantiken römischen domus um 400 verallgemeinert werden kann, lässt sich dem nur spärlichen Befund der archäologischen und literarischen Quellen nicht sicher entnehmen. Die erhaltenen Zeugnisse machen jedoch unmissverständlich deutlich, dass die Heiligen nicht nur Prozesse kollektiver Identitätsstiftung in Gang setzten, sondern auch zum asketischen Rückzug aus der Öffentlichkeit und zur individuellen Annäherung einluden. In ihrer Eigenschaft als Patrone und Interzessoren, die mit den Lebenden über die Grenze des Todes hinweg in einer Handlungsgemeinschaft verbunden blieben, bildeten die Heiligen innerhalb der römischen domus, dem räumlichen Zentrum sozial vermittelter Patronage, eigene Zentren der Macht und eine Form von Patronage, die nicht ohne weiteres in die Strukturen sozialer, zu Freunden und Klienten unterhaltener Patronagebeziehungen integrierbar war: Die Möglichkeit, die Heiligen zu Adressaten persönlicher Anliegen zu 
machen, war eine eigenständige Quelle von Kommunikations- und Handlungsbeziehungen, die nicht die gesellschaftlichen Bindungsverhältnisse reproduzierten, und in denen sich ein tiefgreifendes Veränderungspotential für die Gestaltung von sozialen Beziehungen offenbarte.

Ähnliche Tendenzen wie innerhalb der domus machten sich im Laufe des 5. Jh. auch mit Blick auf die römische Gemeinde und die christliche Sakraltopographie Roms bemerkbar. Anders als in den Schismen des 4. und frühen 5. Jh., in denen die Heiligentopographie im römischen Suburbium keine legitimierende Bedeutung für die Anwärter auf das römische Bischofsamt gehabt hatte, verdeutlicht das Schisma zwischen Symmachus und Laurentius, dass die Bezugnahme auf die apostolischen Gemeindegründer Petrus und Paulus im ausgehenden 5. Jh. eine zentrale Rolle für die bischöfliche Legitimation spielte. Insbesondere Symmachus betrieb eine gezielte Annäherung an den ersten Bischof Roms, indem er die Grablege des Petrus am Vatikan nicht nur $\mathrm{zu}$ einem administrativen und liturgischen Zentrum, sondern zu einer regelrechten Stadt im Kleinen umformte. Symmachus machte vor allem durch seine Umgestaltung des Baptisteriums der vatikanischen Petrusbasilika, die sich am Vorbild des Lateranbaptisteriums orientierte, deutlich, dass sich die Begründungszusammenhänge im Vergleich zu früheren Schismen umkehrten: Das vatikanische Baptisterium wandelte sich von einer Taufstätte für die Pilger zu einem ideellen Bezugspunkt der römischen Gemeinde, die ihrem Bischof hinaus zum Vatikan folgte, wo dieser in der Nachfolge des Petrus die Taufe der Gemeindemitglieder vornahm. Anstelle einer gemeindebezogenen Auffassung des Bischofsamtes, die im 4. Jh. eine Ausrichtung auf den städtischen Raum und die dort lebende plebs bewirkt hatte, trat nun der apostolische Traditions- und Sukzessionsgedanke deutlich stärker in den Vordergrund.

Ein Ausdruck dieser veränderten Vorstellung sind auch die retrospektiven Überformungen, die Schismen des 4. und frühen 5. Jh. aus der Perspektive des ausgehenden 5. Jh. erfuhren. Sowohl im Schisma zwischen Bonifatius und Eulalius als auch in den Auseinandersetzungen zwischen Felix II. und Liberius gewannen nach der späteren Darstellung der hagiographischen Literatur räumlich vermittelte Bezüge auf bischöfliche Vorgänger und einzelne Heilige eine Bedeutung, die sie zu Lebzeiten der historischen Akteure nie gehabt hatten. Diese Art der topographischen Verortung ist ein sprechendes Zeugnis dafür, wie man unter den gewandelten Verhältnissen der Zeit um 500 ein Schisma imaginierte, und bestätigt das Bild, das sich aus den Handlungsstrategien der Akteure im symmachianisch-laurentianischen Schisma gewinnen lässt: Die Bezugnahme der Kontrahenten auf bestimmte Zentren im Suburbium der Stadt war Ausdruck einer im Vergleich mit dem 4. Jh. grundlegend gewandelten Perspektive, in der das mit einzelnen Orten 
einer Heiligen- oder Bischofsmemoria verbundene legitimatorische Element neben einer auf den städtischen Raum bezogenen und durch den sozialen Bezugsrahmen einer Handlungsgemeinschaft von Bischof und populus begründeten Legitimation an Bedeutung gewann.

Begleitet war dieser Perspektivenwechsel von einer tiefgreifenden urbanistischen Umgestaltung des Stadtbildes, das infolge des rapiden Bevölkerungsrückgangs und der partiellen Auflassung von Wohnbereichen zunehmend an Kohärenz verlor. Für das spätantike Rom wurde seit dem 5 . und vor allem 6 . Jh. eine fleckenförmige Besiedlung charakteristisch, wie sie in ähnlicher Form zuvor bereits im Suburbium der Stadt bestanden hatte. Im Stadtgebiet bildeten sich einzelne Siedlungsinseln und -kerne, die mit unbebauten Flächen abwechselten. Eine konsequente symbolische Trennung zwischen der Stadt als der Welt der Lebenden und dem extra muros gelegenen Raum, in dem die Toten ihren Platz hatten, wurde zunehmend aufgegeben und führte dazu, dass sich die Räume einander strukturell anglichen: Das Ergebnis war eine neue, polyzentrische Raumordnung, in der nicht eine Gegenüberstellung von Stadt und Suburbium dominierte, sondern einzelne Inseln den gesamten intra wie extra muros gelegenen Raum strukturierten.

Diese zunehmende Nuklearisierung des Stadtbildes bildete eine wesentliche Voraussetzung dafür, dass auch in der christlichen Sakraltopographie die Gegenüberstellung von Stadt und Suburbium, die während des 4. Jh. durch den Ausbau der Katakomben und Bestattungsanlagen akzentuiert worden war, an raumorganisierender Bedeutung einbüßte. Während noch zu Beginn des 5. Jh. Stadt und Suburbium getrennte liturgische Zonen bildeten, wurden im weiteren Verlauf des 5. Jh. die drei wichtigsten suburbanen Basiliken, S. Pietro, S. Paolo f.l.m. und S. Lorenzo f.l.m., durch die bischöfliche Stationsliturgie und die reguläre liturgische Versorgung mit dem städtischen Titelklerus in die städtische Sakraltopographie einbezogen. Dieser Ausdehnung des bischöflichen Aktionsradius über die Grenzen der Stadt hinaus entsprach umgekehrt ein Verlust an innerer Kohärenz. Obwohl das bis zum 8. Jh. noch weiter ausgebaute Prozessionswesen der bischöflichen Stationsliturgie bereits in der zweiten Hälfte des 5. Jh. beachtliche Ausmaße erreichte, bewirkte es keine Einbeziehung des städtischen Raums, sondern diente der punktuellen Begegnung des Bischofs mit den einzelnen Kirchen und den dort versammelten Klerikern und Gläubigen. Die Bischofsliturgie schuf damit einen nur lockeren Zusammenhang zwischen einzelnen Inseln von städtischen Kirchen und bischöflichen Basiliken, deren zentrale Punkte - die Bischofsbasiliken - sich gleichmäßig auf die Stadt und das Suburbium verteilten.

In das fortgeschrittene 5. Jh. fallen damit die Anfänge einer neuen polyzentrischen Raumordnung, deren Konturen sich im Laufe des 6. Jh. weiter ausbildeten, indem sich vor allem die Heiligen zu Bezugspunkten 
lokaler Zentren der Identitätsstiftung entwickelten. Komplementär zur verstärkten Verlagerung der bischöflichen Präsenz in die Heiligentopographie des Suburbiums begannen auch die Heiligen in die Stadt einzuwandern: Noch vor den Reliquientranslationen des 7. und 8. Jh. wurden mehrere Titelkirchen seit dem 6. Jh. nach den Heiligen der nächstgelegenen Coemeterien umbenannt. Der damit verbundene Perspektivenwandel auf den städtischen Raum wird vor allem in der römischen Hagiographie fassbar: In den Legenden löste sich der städtischen Raum in eine Vielzahl gleichförmiger Orte und Zentren auf, die mit der Erinnerung an die Heiligen verbunden waren, und die aufgrund ihrer Stereotypie keinen Eindruck von einem städtischen Zusammenhang vermittelten. Unter den Vorzeichen der Heiligenverehrung wurde damit eine fragmentierende Sicht auf den städtischen Raum akzentuiert, die sich seit dem 6. Jh. auch innerhalb der Kirchenräume bemerkbar machte: In den mit Heiligenreliquien versehenen Nebenaltären entstanden eigenständige Bezugspunkte der Verehrung und der eucharistischen Liturgie, die die traditionelle Einheit von Altar, Kirchenraum und der in der Eucharistiefeier verbundenen Gemeinde infrage stellten.

So unterschiedlich diese in den einzelnen Teilkapiteln erarbeiteten Befunde im Detail sind, zeigen sich in ihnen strukturell vergleichbare Phänomene der Schwächung und Fragmentierung von innerweltlichen Sozialbeziehungen durch das Heiligengedenken. Die Besucher der Triklia unter S. Sebastiano suchten die Nähe besonderer Fürsprecher, die als Mittler zwischen der göttlichen und der menschlichen Welt auftraten und ihnen Wege zum Heil eröffneten, die - im Unterschied etwa zur Kirchenbuße - nicht über die Gemeinden führten. Kaiser Konstantin rekurrierte auf die in den Heiligen verkörperte Mittlerstellung, um die Lösung des spätantiken Kaisers aus menschlichen Handlungszusammenhängen zu demonstrieren: Der Heiligenkult bot ihm ein kulturelles Modell, um den Anspruch des Kaisers auf kultische Verehrung an seine sterblichen Überreste zu binden und damit zu verdeutlichen, dass seine übermenschlichen Qualitäten nicht - wie bei der Divinisierung - auf menschlicher Zuschreibung beruhten, sondern als Eigenschaften in ihm selbst ,verkörpert“ waren. In ihrer Eigenschaft als städtische Patrone, die den Heiligen seit dem ausgehenden 4. Jh. in Rom wie in anderen Städten des Römischen Reichs zuwuchs, machte sich die Mittlerrolle der Heiligen nicht mehr nur in der Interzession für die Sündenvergebung und das Seelenheil bemerkbar, sondern betraf in umfassender Weise auch die diesseitigen Angelegenheiten. Den heiligen Patronen wurde eine unbegrenzte Macht zugeschrieben, die einen wirksameren Schutz gewährte, als es die Formen politischer Organisation und Herrschaftsbildung zu leisten imstande waren. Obwohl die Heiligen zu Patronen ganzer Städte avancierten, wurde damit ein wesentliches Prinzip städtischer Identi- 
tätsstiftung - die Fähigkeit, sich als Bürgergemeinde zu organisieren und politische Autoritätsstrukturen auszubilden - außer Kraft gesetzt: Macht und Autorität wurden nicht mehr durch das soziale und gesellschaftliche Handeln von Gruppen begründet, sondern unter Rekurs auf die göttliche Macht „von oben“ abgeleitet. Dass dieses Prinzip quer zu den traditionellen Formen und Mechanismen politischer und gesellschaftlicher Autoritätsbildung lag, verdeutlicht die Heiligenverehrung im Kontext der römischen domus: Dort bildeten Heiligenoratorien eigene Zentren der Macht, die außerhalb der sozialen Strukturen von Patronage- und Klientelbeziehungen individuelle Annäherungen an die Heiligen ermöglichten. Auch der Umstand, dass sich im Rom des späteren 5. Jh. die Heiligen verstärkt zu Kristallisationspunkten lokaler Identitäten entwickelten, die an die Stelle der Stadt als Handlungseinheit traten, und dass der römische Bischof seine Autorität nicht mehr aus der Bezogenheit auf die Gemeinde, sondern aus der Petrusnachfolge ableitete, zeigt die Konsequenzen einer Entwicklung, in deren Verlauf die Beziehung zu heiligen Patronen und Fürsprechern sozial und politisch begründete Formen der gesellschaftlichen Organisation in den Hintergrund zu drängen begann.

In nur wenigen Beiträgen zur spätantiken Heiligenverehrung ist dieser strukturelle Zusammenhang zwischen der Entwicklung des Heiligenkults in der Spätantike und der damit einhergehenden Schwächung politischer und sozialer Formen der gesellschaftlichen Organisation so klar herausgearbeitet worden wie in einem Aufsatz von Jochen Martin, in dem er die Heiligenverehrung nicht allein aus den Voraussetzungen ihrer Funktion innerhalb der christlichen Gemeinden interpretiert, sondern in einen weiteren Kontext von Formen sozialer und politischer Autoritätsbildung innerhalb der spätantiken Gesellschaft im Westen des Römischen Reichs stellt. ${ }^{2}$ Martin deutet die von ihm analysierten Phänomene als Ausdruck eines umfassenden kulturellen Wandels, den er um die Wende vom 2. zum 3. Jh. beginnen lässt und an der zunehmenden Akzentuierung des Interzessionsgedankens in der Heiligenverehrung festmacht. Die Entwicklung der Heiligen zu Interzessoren und ihre Entrückung aus menschlichen Handlungszusammenhängen sei ein Ausdruck dessen, dass Autorität zunehmend nicht mehr sozial und innerweltlich, sondern religiös und unter Verweis auf die göttliche Beauftragung oder Autorisierung begründet worden sei. ${ }^{3}$ Diese überzeugende Beobachtung kann sich nicht nur auf die Rolle der Heiligen als Interzessoren und Patrone stützen, sondern auch auf strukturell vergleichbare Phänomene im kaiserlichen Selbstverständnis seit dem 3. Jh. verweisen. Im Unterschied zur

\footnotetext{
Vgl. Martin 1990.

Prägnant formuliert ebd., 461: „Macht tendiert... dazu, zu einem Phänomen der Beziehungen zwischen Menschen und Göttern zu werden; soziale und politische Beziehungen werden zunehmend religiös interpretiert. Hier deuten sich Veränderungen an, die man als einen Wandel des Kommunikations- oder Verstehenssystems bezeichnen kann.“
} 
frühen und hohen Kaiserzeit erklärten die römischen Herrscher seit dieser Zeit zunehmend, als Beauftragte der Götter zu handeln, und traten damit als Mittler zwischen der göttlichen und der menschlichen Welt auf, die ihr militärisches und politisches Handeln unter Berufung auf eine göttliche Beauftragung begründeten und auch im Bereich der religiösen Kommunikation ihren Anspruch auf Göttlichkeit nicht mehr, wie bis dahin üblich, aufgrund besonderer Leistungen erhoben. Die Begründungszusammenhänge kehrten sich diametral um: Die Herrscher leiteten ihre Autorität und den Anspruch auf göttliche Verehrung aus ihrer Nahbeziehung zum Göttlichen ab; Handeln und der sichtbare Erweis von Macht bildeten nicht mehr die Voraussetzung für die Zuschreibung von Göttlichkeit, sondern wurden umgekehrt mit dieser begründet. ${ }^{4}$

Kennzeichnend ist demnach, dass Martin den von ihm konstatierten Wandel in den Kommunikationsbeziehungen nicht als eine rein auf den Heiligenkult beschränkte Angelegenheit, sondern als Ausdruck eines weiteren mentalitätsgeschichtlichen Zusammenhangs begreift: In dem Maße, in dem seit dem 3. Jh. n. Chr. Kommunikation nicht mehr im Rahmen menschlicher Handlungsmaßstäbe interpretiert, sondern religiös motiviert wurde, sei die Autonomie sozialer und politischer Handlungszusammenhänge verloren gegangen - in der politischen Organisation ebenso wie in Gemeinschaften und Gruppen, deren Kommunikationsbeziehungen eo ipso religiös fundiert waren, wie in den christlichen Gemeinden. Martins Ansatz bewegt sich damit - in den methodischen Voraussetzungen wie in den inhaltlichen Schlussfolgerungen - auf einer ähnlichen Linie wie Peter Browns vielzitierter Essay zum spätantiken Heiligenkult im Westen des Römischen Reichs. Auch für Brown liegt der Schlüssel zum Verständnis der gesellschaftlichen Bedeutung des spätantiken Heiligenkults in der Eigenschaft der Heiligen als mächtige Patrone und Interzessoren. Als Menschen, die durch ihr Martyrium zu Gott entrückt wurden, hätten sie eine neue Form der Patronage begründet, die paradoxerweise gleichzeitig von großer Distanz und von ,intimacy“ und Nähe der Heiligen zu ihren Verehrern geprägt gewesen sei. ${ }^{5}$ Brown fasst dies als eine neue Qualität von Macht auf, die er aber - ähnlich wie Martin - nicht allein auf den Heiligenkult beschränkt wissen will, sondern in den Kommunikationsbeziehungen der spätantiken Gesellschaft insgesamt am Werk sieht: Einer seit der Wende vom 2. zum 3. Jh. hervortretenden Tendenz, das hierarchische Gefälle in Machtrelationen und Patronagebeziehungen zu betonen, hätten die Heiligen durch ihre übermenschliche

\footnotetext{
$4 \quad$ Für diese Entwicklung des spätantiken Kaisertums von einer - im Sinne Max Webers - charismatischen Herrschaft zu einem Gottesgnadentum vgl. auch Martin 1984, bes. 115-120.

5 Brown 1981, bes. 50-68; 106-127.
} 
Mittlerstellung zugleich weiteren Vorschub geleistet und ein menschlicheres Antlitz verliehen. ${ }^{6}$

Die Beobachtungen von Brown und Martin sind richtungweisend und machen deutlich, wie tief die sozialen Erscheinungsformen des Heiligenkults in den Strukturen der spätantiken römischen Kultur wurzelten. Dennoch erscheint es angebracht, das Phänomen einer im Heiligenkult sichtbaren Tendenz zur Schwächung innerweltlich begründeter Sozialbeziehungen nicht allein an der Macht und Mittlerstellung der Heiligen festzumachen und in stärkerem Maße kulturelle Aspekte in Rechnung zu stellen, die spezifisch christlicher Prägung sind. Bereits die Refrigerien unter S. Sebastiano haben deutlich gemacht, dass die Entrückung der Märtyrer aus menschlichen Kommunikationszusammenhängen entscheidend durch die Eigenheiten der christlichen Memorialkultur bedingt war: Erst unter der Voraussetzung, dass Lebende und Tote im Handeln miteinander verbunden blieben, diese Beziehung jedoch sozial nicht mehr als solche erfahrbar war, kam eine Distanzierung der Heiligen aus innerweltlich begründeten Handlungszusammenhängen zum Tragen, die zu Lebzeiten der Märtyrer durch soziale Gesten der Verdemütigung wirksam konterkariert worden war. Diese Transzendierung innerweltlicher Handlungszusammenhänge leistete jedoch nicht nur einer Entrückung der heiligen Interzessoren Vorschub, sondern barg zugleich eine weiterreichende, strukturelle Tendenz zu einer Schwächung innerweltlicher Handlungsbeziehungen in sich. Infolge der christlichen Konzeptualisierung des Totengedenkens entwickelten sich die Verstorbenen zu eigenständigen Adressaten interpersonaler Beziehungen in einer Weise, in der sie es in der paganen römischen Tradition der Totenmemoria nicht gewesen waren: Während das nichtchristliche Totengedenken den Toten in den sozialen Bezügen kommemorierte, die er zu seinen Lebzeiten zu denjenigen, die sich seiner erinnerten, unterhalten hatte, entwickelte sich in der christlichen Memorialkultur aufgrund der Ausdehnung von Handlungszusammenhängen über die Grenze des Todes hinweg die Relation zu den Toten zu einem beziehungsgestaltenden Faktor sui generis. ${ }^{7}$

6 Zu den neuen „Stilen der Macht“ und der zunehmenden hierarchischen Distanz in menschlichen Sozialbeziehungen vgl. Brown 1995 (1978), bes. 28-30, 75f. Zur gesamtgesellschaftlichen Bedeutung des Heiligenkults für die soziale Kommunikation vgl. pointiert dens. 1981, 21f.: „The cult of the saints involved imaginative changes that seem, at least, congruent to changing patterns of human relationships in late-Roman society at large... Let us attempt to see it (scil. den Heiligenkult) as part of a greater whole - the lurching forward of an increasing proportion of late-antique society toward radically new forms of reverence... with new forms of exercise of power, new bonds of human dependence new, intimate, hopes for protection and justice in a changing world."

$7 \quad$ Zu den Konsequenzen s. u., S. 535f. 
Der Vorgang einer Transzendierung von Kommunikationsbeziehungen, der nicht nur die Heiligen, sondern die Toten insgesamt zu eigenständigen Subjekten des Handelns machte, ist jedoch letztlich nur ein Phänomen der Veränderung zwischen antiker und christlicher Memoria, ebenso wie das Totengedenken nur ein Bereich ist, in dem die christliche Memorialkultur zu einer Schwächung innerweltlich erfahrbarer Sozialbeziehungen führte. Exemplarisch deutlich wird dies in der Vervielfältigung von Messfeiern und einer damit einhergehenden Auffassung von der Eucharistie, die in immer stärkerem Maße ihren Charakter als gemeinschaftliche und Gemeinschaft erzeugende Darbringung verlor. Wie bereits ausgeführt, ${ }^{8}$ ist dies nicht aus der Verehrung der Heiligen bzw. der in den Altären rekondierten Reliquien zu erklären, sondern vielmehr die Konsequenz einer veränderten Akzentuierung der in der Eucharistiefeier wirksamen memorialen Gabentauschbeziehungen: In dem Maße, in dem die eucharistische oblatio sich von der Darbringung durch die Gemeinde auf das dargebrachte Opfer und den zelebrierenden Liturgen verlagerte, trat ihre soziale Dimension als einer für die Gemeinschaft erbrachten Leistung in den Hintergrund: Der Tausch zwischen Gabe und Gedenken wurde nicht primär auf der Ebene der menschlichen Handlungsbeziehungen wirksam, sondern zwischen den Gebern und Gott vollzogen. Ihren äußeren Ausdruck fand diese Tendenz im verstärkten Aufkommen von Votivmessen, die zwar nur über einen kleinen Teilnehmerkreis verfügten, aber den entscheidenden Zweck erfüllten, sich bei Gott durch die Opfergabe in Erinnerung zu bringen.

Diese Beobachtung gibt Anlass dazu, das Veränderungspotential der christlichen Memorialkultur für die Gestaltung von Sozialbeziehungen nicht allein auf das Totengedenken zu beschränken, sondern dieses in einen weiteren Kontext von Formen der sozialen Vergemeinschaftung zu stellen, in denen memoriale Beziehungen wirksam wurden. Dabei wird deutlich werden, dass die entscheidende Differenz zwischen der antiken und der christlichen Memorialkultur nicht in der Transzendierung menschlicher Handlungsbeziehungen durch das christliche Totengedenken, sondern auf der Ebene der Memoria selbst liegt, die im Christentum nicht als ein rein sozialer, zwischen Menschen vollzogener Gabentausch konzeptualisiert wurde. Abschließend sollen dieser Zusammenhang näher ausgeführt und die Dimensionen des damit einhergehenden kulturellen Wandels verdeutlicht werden. Veränderungen in der Konzeptualisierung von memorialen Gabentauschbeziehungen machten sich vor allem in derjenigen Vergemeinschaftungsform der antiken Kultur bemerkbar, für die das Wechselspiel von Gabe und Gedenken eine formative Bedeutung hatte, und die zugleich als eine der

Hierzu s. o., S. 415-424. 
charakteristischsten Ausprägungen der antiken Memorialkultur gelten kann: der antiken Stadt.

\section{2. Memoria als Gabentausch oder: das Ende der antiken Stadt}

Die Frage nach dem Stellenwert der Memoria in der römischen Kultur umfasst deutlich mehr als nur den Kult und die Verehrung der Toten. Memorialpraktiken machten einen großen Teil dessen aus, was die städtische Kultur des römischen Imperiums auszeichnete. Exemplarisch fassbar wird dies in den Inschriften auf Statuenbasen, die im spätantiken Rom von Kollegien oder städtischen Gemeinden für Angehörige der städtischen Oberschicht zu deren Lebzeiten ad sempiternam memoriam oder als ein perenne monumentum errichtet wurden. ${ }^{9}$ Sie erhielten die Erinnerung an die Geehrten aufrecht und waren Teil eines immer wieder erneuerten Handlungszusammenhangs, in dem wechselseitig Leistungen auf der einen, Distinktion und Kommemoration auf der anderen Seite zugewiesen wurden: Mit den Statuen, die Kollegien und Gemeinden im spätantiken Rom für ihre Patrone errichten ließen, honorierten sie die von ihnen empfangenen Zuwendungen durch eine Memorialgabe, die gleichzeitig Ausdruck dankbaren Gedenkens war und den Geehrten und seine Familie verpflichten sollte, dieses Gedenken auch weiterhin durch entsprechende Leistungen aufrechtzuerhalten.

Dieser Zusammenhang von Gabe und memorialer Gegengabe war tief verankert in der römischen Gesellschaft, in der das reziproke Verhältnis des Gabentauschs weite Bereiche der patronal geprägten sozialen Beziehungen umfasste. ${ }^{10}$ Dass beneficia ihren Empfänger banden und ihn zur Gegengabe der gratia verpflichteten, war ein ehernes Prinzip, das Cicero ebenso geläufig war wie 400 Jahre später Augustinus. ${ }^{11}$ Die Bedeutung, die die Erinnerung in diesem wechselseitigen Verhältnis spielte, haben Autoren wie Cicero und Seneca, die in ihren Schriften ethische Prinzipien zur Praxis des Gebens, Empfangens und Erwiderns von Gaben formulierten, die bis in die Spätantike hinein aktuell blieben, ${ }^{12}$ explizit zur Sprache gebracht. ${ }^{13}$ Undankbarkeit

$9 \quad$ Vgl. die Übersicht bei Niquet 2000, 77, 262-283. Zu diesem ausgeprägten Memoriadiskurs in stadtrömischen Statuenweihungen der Spätantike vgl. Alföldy 2001, 14.

10 Zur ausgeprägten Ethik der Reziprozität vgl. Bolkestein 1939, 317f.; Saller 1982, 27-30; zur intensiven Ausprägung von Gabentauschbeziehungen in der römischen Gesellschaft s. ebd., 121 124; Martin 1994, 105-110.

11 Cic., off. 1, 48: non reddere viro bono non licet; vgl. Sen., benef. 3, 1, 1: non referre beneficiis gratiam et est turpe et aput omnes habetur. Mit beinahe identischer Formulierung wird die Bindungskraft der Gabe hervorgehoben von Cic., off. 1, 58 (patria und parentes, quorum beneficiis maximis obligati sumus) und Aug., conf. 6, 10 (potentissimus senator, cuius et beneficiis obstricti multi et terrori subditi erant).

12 Vgl. dazu u., S. 528f.

13 Für eine Analyse vgl. zuletzt Pickert 2005, 23-28. 
und mangelndes Gedenken der Empfänger für erhaltene Wohltaten - ingratus und immemor $\mathrm{zu}$ sein - bildeten regelrechte Synonyme: ${ }^{14}$ Die Erinnerung selbst galt bereits als Ausdruck des Danks. ${ }^{15}$ Dementsprechend sollten auch die Wohltaten so gewählt sein, dass sie ein dauerhaftes Gedenken aufseiten der Empfänger gewährleisteten - ein Ziel, dem sowohl die Beschaffenheit der Gabe $^{16}$ als auch der zeitliche Rhythmus des Gebens ${ }^{17}$ dienten. Erinnerung hielt einen Kreislauf von Leistungen und Gegengaben in Gang, der bis über den Tod hinaus wirksam blieb: Gaben verpflichteten auch kommende Generationen zur Dankbarkeit und begünstigten auf diese Weise den dauernden Ruhm und das Nachleben des Wohltäters, ${ }^{18}$ wie es beispielsweise in den oben erwähnten Statuen als perennia monumenta seinen sinnfälligen Ausdruck fand. Dadurch wurde ein andauerndes Wechselspiel von beneficium und gratia begründet, in dem die Memoria zugleich als Motor und als Ziel fungierte: Erinnerung hielt nicht nur die wechselseitige Verpflichtung zum fortgesetzten Geben und Erwidern lebendig, sondern begründete auch den Nachruhm des Wohltäters, ein dauerhaftes Gedenken, das ihm - gleichsam als Dank und Gegengabe für seine materiellen Leistungen - zuteil wurde.

Ein zentrales Feld, auf dem der Tausch von Gabe und Gedenken im oben beschriebenen Sinne wirksam wurde, war die - im folgenden idealtypisch als solche bezeichnete - antike Stadt. ${ }^{19}$ Er äußerte sich dort in der

14 Cic., off. 2, 63: danda igitur opera est, ut... beneficiis quam plurimos adficiamus..., ut iis ingratis esse non liceat. Omnes enim immemorem beneficii oderunt. Sen., benef. 3, 1, 3: ingratus, qui beneficium accepisse se negat, quod accepit, ingratus est, qui dissimulat, ingrates, qui non reddit, ingratissimus omnium, qui oblitus est. Ebd., 3, 4, 3: memoria gratum facit. Die Auswahl eines würdigen Empfängers ist daran gebunden, dass er integer, simplex, memor und gratus ist (ebd., $4,11,1)$.

15 Ebd., 3, 2, 2: qui meminit, sat sine inpendio gratus est.

16 Speisungen und Investitionen in das Spielwesen sichern aufgrund ihrer Vergänglichkeit nur eine geringe memoria und sind daher aus Ciceros Sicht als Verschwendung einzustufen (Cic., off. 2, 55: prodigi, qui epulis et viscerationibus et gladiatorum muneribus ludorum venationumque apparatu pecunias profundunt in eas res, quarum memoriam aut brevem aut nullam omnino sint relicturi; vgl. auch ebd., 2, 56: Beim Publikum dieser Veranstaltungen stirbt die Erinnerung zugleich mit dem Genuss: una cum satietate memoria quoque moriatur voluptatis). Monumente begründen demgegenüber einen dauerhafteren Anspruch auf Erinnerung; sie sind in posterum gratiora (ebd., 2, 60).

17 Sen., benef. 2, 24, 1: „Man muss nichts energischer gewährleisten, als dass in uns die Erinnerung (memoria) an die Verdienste erhalten bleibt, die in schneller Folge erneuert werden muss, weil nur der Dank abstatten kann, der sich erinnert, und derjenige, der sich erinnert, ihn abstattet" (nibil magis praestandum est, quam ut memoria in nobis meritorum haereat, quae subinde reficienda est, quia nec referre potest gratiam, nisi qui meminit et, qui meminit, eam refert).

18 Cic., off. 2, 63: Die Erinnerung an beneficia wird auch an die Kinder der Empfänger, die sich dadurch verpflichtet fühlen, weitergegeben. Cic., off. 2, 23: Wohlwollen sichert im Unterschied zur Furcht nicht nur Dauer und Beständigkeit der Herrschaft (diurnitas), sondern Ewigkeit (perpetuitas).

19 Angesichts der Fülle an historisch und regional unterschiedlichen Ausprägungen antiker Städte im griechisch-römischen Kulturbereich ist die Rede von „der“ antiken Stadt nur im Sinne einer idealtypischen Begriffsbildung möglich. Zum idealtypischen Verfahren als einer spezifischen Methode der Kulturwissenschaften, die auf die Erfassung von historischen Phänomenen 
Form regelmäßiger Leistungen, die von den Oberschichten der Städte für die Bürger erbracht und von diesen mit Ehrungen für ihre Wohltäter beantwortet wurden. Der memoriale Aspekt dieses für die Identität der antiken Stadt fundamentalen ${ }^{20}$ Gabentauschs tritt vor allem in Bauwerken (monumenta) ${ }^{21}$ oder Statuen, die den Geehrten errichtet wurden, sinnfällig zutage; er äußerte sich aber auch in stärker ephemeren Leistungen wie Spielstiftungen, kollektiven Speisungen und anderen - euergetisch wie ob honorem erbrachten ${ }^{22}$ largitiones und munera, die ebenfalls darauf berechnet waren, die Erinnerung an ihren Geber lebendig zu halten. ${ }^{23}$ Das monumentale Erscheinungsbild, das den Raum der antiken Stadt in seinem materiellen Sinne konstituierte, gehört demnach in einen umfassenderen Zusammenhang intensiv betriebener euergetischer Handlungsbeziehungen: Die Bauten und urbanen Strukturen der antiken Stadt sind nicht ablösbar von den Sozialbeziehungen, die sie

ausgerichtet sind und sich darin von den Gesetzeswissenschaften und deren Verfahren (systematische Erfassung der Wirklichkeit durch Gesetze, der das Individuelle untergeordnet ist) unterscheiden, vgl. M. Weber ${ }^{71988 ~(1904), ~ 161-214 . ~ F u ̈ r ~ d e n ~ h i e r ~ i n t e r e s s i e r e n d e n ~}$ Zusammenhang ist wichtig, dass Weber den Idealtyp als eine einseitige und rein gedankliche Steigerung von bestimmten Gesichtspunkten versteht, die auf diese Weise ein Gedankenbild ergeben, das ,in seiner begrifflichen Reinheit... nirgends in der Wirklichkeit empirisch vorfindbar“" ist (ebd., 190f.). Idealtypen lassen sich also nicht einfach in historische Realitäten überführen; sie weisen aber Wege, konkrete historische Erscheinungsformen zu interpretieren, und erlauben durch die gedankliche Zuspitzung, deren Eigenarten klarer gegeneinander abzusetzen. Zur Möglichkeit, einen Idealtyp der antiken Stadt auf der Grundlage des euergetischen Gabentauschs zu entwickeln, vgl. - in direkter Auseinandersetzung mit Max Webers idealtypischem Entwurf der antiken Stadt - Martin 1994.

20 Die Dimensionen des antiken Euergetismus und seine Bedeutung für das monumentale Erscheinungsbild und vor allem für die Sozialbeziehungen, die den städtischen Bürgerverband konstituierten, hat Paul Veyne herausgearbeitet; vgl. Veyne 1988 (1976), 22 zur Definition des Euergetismus (Freigebigkeit gegenüber Kollektiven wie Städten oder Kollegien); zur soziologischen Relevanz für die antike Stadt s. allgemein ebd. 101f. u. im folgenden S. 511f.

21 Schon der Begriff monumentum selbst signalisierte den Anspruch auf Erinnerung; vgl. die etymologische Definition von Festus 123, 7-9: monimentum est, quod et mortui causa aedificatum est et quicquid ob memoriam alicuius factum est, ut fana, porticus, scripta et carmina (zum Beleg vgl. Häusle 1980, 32, Anm. 77).

22 Veyne 1988 (1976), 22f. hebt zurecht hervor, dass die formal freiwillig erbrachten Euergesien und die ob honorem, mit der Übernahme eines städtischen Amtes verbundenen Leistungen in denselben Funktionszusammenhang gehören, da beide gegenüber der Bürgerschaft eine Verpflichtung zum Geben begründeten. Zuletzt hat Eck 1997 die Trennung zwischen amtlich zu erbringenden und freiwilligen euergetischen Leistungen betont und die Bedeutung des Euergetismus für die Städte der römischen Kaiserzeit relativiert; unter Gabentauschbeziehungen ist diese Differenzierung jedoch sekundär.

23. Vgl. den umfangreichen Katalog der von Cic., off. 2, 60 angeführten Beispiele für largitiones (Mauern, Docks, Häfen, Wasserleitungen und daneben andere, nicht unmittelbar auf den Nutzen der res publica bezogene Leistungen, wie Theater, Portiken und Tempelbauten). Seit dem 3. Jh. scheinen die städtischen Eliten weniger in Bauten und den öffentlichen Raum investiert und sich stattdessen stärker auf ephemere Leistungen wie das Spielwesen und auf die Klienten als soziale Bezugsgruppe konzentriert zu haben (vgl. Borg/Witschel 2001, bes. 90-118; kritisch Haug 2003, 299f.). 
hervorbrachten - was im Umkehrschluss bedeutet, dass allein die siedlungsgeographische Kontinuität in der Nutzung antiker Städte kein adäquates Kriterium für das Fortbestehen der antiken Stadt im frühen Mittelalter bedeutet.

Die Ethik eines memorialen Gabentauschs war für die Identität der antiken Stadt von fundamentaler Bedeutung. Dies gilt in gleicher Weise für die griechischen Poleis der hellenistischen Zeit wie auch für die kaiserzeitlichen Städte, obwohl die sozialen und politischen Voraussetzungen, auf denen die Gabentauschbeziehungen beruhten, unterschiedlich waren. In der griechischen Polis war die Vorstellung vorherrschend, dass seine Zugehörigkeit zur Stadt und zum Bürgerverband einen Euergeten dazu verpflichtete, seinen Reichtum zum Wohl der Bürgerschaft zu verwenden. Umgekehrt honorierten die Bürger diese Leistungen für das städtische Gemeinwesen, indem sie den Gaben die schuldige Anerkennung erwiesen. ${ }^{24}$ Die Verpflichtung des Euergeten, sein Vermögen zum Wohl der Bürger einzusetzen, und die in den Ehrendekreten hervorgehobene Auszeichnung, die dem Euergeten durch die Ehrung seiner Mitbürger zuteil wurde, signalisieren eine ausgeprägt egalitäre Beziehung zwischen beiden Seiten, die eben deswegen so stark hervorgehoben wurde, weil sie durch die historische Entwicklung - die Etablierung einer vermögenden Honoratiorenschicht an der Spitze der griechischen Poleis in hellenistischer Zeit - zunehmend infrage gestellt wurde. ${ }^{25}$ Nur durch intensiv betriebene Euergesien war es möglich, die soziale Distinktion dieser Gruppe zu wahren und zugleich mit einer ausgeprägten Tradition der politischen Gleichheit aller Bürger zu verbinden. Die dadurch bedingte hohe Frequenz dieses immer wieder aktualisierten euergetischen Gabentauschs entfaltete eine starke gemeinschaftsstiftende Wirkung: Geber und Empfänger artikulierten ihre Identität als Bürger und konstituierten durch das Wechselspiel von Gabe und Ehrung die Stadt als politische Handlungseinheit.

In Rom und in den kaiserzeitlichen Städten des Reiches, die sich in ihren Strukturen an Rom orientierten, ${ }^{26}$ äußerte sich dieser Gabentausch zwar auf andere Weise als in Griechenland. Der Euergetismus hatte im Westen ein stärker hierarchisch geprägtes Erscheinungsbild: Anders als bei der für die griechischen Städte typischen diskursiven Betonung eines egalitären Verhältnisses zwischen Bürgern und Euergeten wurde in den römischen Städten das politische Gefälle zwischen den Oberschichten und den Empfängern der Gaben deutlich stärker betont. ${ }^{27}$ Doch auch wenn in der

\footnotetext{
$24 \quad$ Vgl. Veyne 1988 (1976), 210-212, 269-271 (Verpflichtung der Euergeten gegenüber den Bürgern zur Gabe); 239-248 (Ehrzuweisungen als Gegengabe).

25 Zum egalitären Diskurs der Ehreninschriften für Euergeten s. ebd., 216f., 248.

26 Martin 1994, $108 \mathrm{f}$.

$27 \quad$ Zu dieser Differenz s. Veyne 1988 (1976), bes. 312-315.
} 
römischen Tradition die klientelaren Beziehungen zwischen den städtischen Oberschichten und der städtischen Bevölkerung stärker zum Tragen kamen, war deren Rolle dennoch nicht auf den Status eines passiven Empfängers reduziert. Auch hier waren die Leistungen eines Patrons an entsprechende Verhaltenserwartungen seiner Klientel gebunden, die einen hohen Verpflichtungsgrad erreichten. Und auch hier entfalteten diese Gabentauschbeziehungen eine identitätsstiftende Wirkung auf städtischer Ebene, obwohl die Pflicht zum Geben nicht, wie in der hellenistischen Polis, auf der Vorstellung gründeten, dass der Wohltäter als Bürger seinen Mitbürgern das Schuldige erwies. Die in den kaiserzeitlichen Städten des Westens wirksame Ausrichtung patronaler Beziehungen auf die Stadt ergab sich aus der politischen Tradition Roms, an der sich auch die städtische Kultur des römischen Reichs, soweit sie nicht durch die griechische Polisstruktur geprägt war, maßgeblich orientierte. Die Leistungen der römischen Aristokratie waren auf die res publica bezogen: Sie allein vermittelte Ehrungen - vor allem in Form von politischen Ämtern -, die von dieser Oberschicht als statusrelevante Auszeichnung angesehen wurden. Auch die patronalen Beziehungen, die römische Senatoren zu ihren Anhängern unterhielten, waren eingebunden in das politische System, zu dessen Aufrechterhaltung im Inneren sie entscheidend beitrugen. ${ }^{28}$ Diese politische Bezogenheit klientelarer Bindungen in Rom und den vom Vorbild Roms abhängigen Städten des Imperiums führte - ähnlich wie der Euergetismus in der hellenistischen Polis - zu einer prägenden Bedeutung von Gabentauschbeziehungen für die Identität der kaiserzeitlichen Stadt.

Dieser Befund hat Konsequenzen für die Bewertung der gesellschaftlichen Bedeutung der Memoria, die wir bereits als wesentliches Element dieses Gabentauschs zwischen den städtischen Eliten und der Bürgerschaft bestimmt haben. Erinnerung wurde in der römischen Welt nicht nur und nicht einmal primär in den Grabmonumenten entlang der städtischen Ausfallstraßen thematisiert, sondern ist in einen weiteren Funktionszusammenhang euergetischer Handlungsbeziehungen zu stellen. Auch wenn die lateinischen Autoren der Ansicht waren, das Grab und das Totengedenken seien der Ursprung und die Keimzelle aller Memoria, ${ }^{29}$ ist die Relation eine

28 Zur Komplementarität von öffentlicher und privater Sphäre und den gesellschaftlichen Regelungs- und Kontrollfunktionen, die die Senatoren nicht nur als Magistrate, sondern auch als patres und als Patrone ausübten, vgl. o., S. 120, 385f. Im Unterschied zu Rom können in Griechenland vergleichbare patronale Abhängigkeitsbeziehungen nicht als eine Form von Euergetismus aufgefasst werden (vgl. Veyne 1988 [1976], 167f.).

29 Varro, ling. 6, 49: monimenta quae in sepulcris, et ideo secundum viam, quo praetereuntes admoneant et se fuisse et illos esse mortalis. ab eo cetera quae scripta ac facta memoriae causa monimenta dicta. Die Funktion des Grabmonuments ist primär die Ermahnung, der eigenen Vergänglichkeit eingedenk zu sein; im übertragenen Sinne ist jedoch alles, was der Erinnerung wegen geschrieben und getan wird, ein 
umgekehrte: Die Erinnerung hatte ihren Ort und ihr Zentrum im städtischen Raum und den dort begründeten Kommunikations- und Interaktionsbeziehungen; am Grab und in der Totenmemoria wurden ähnliche Bezüge wirksam, wie sie bereits zu Lebzeiten des Toten kennzeichnend gewesen waren.

Darauf, dass das antike Totengedenken diesen euergetischen Handlungszusammenhang von Leistungen des Gebers und dem Gedenken der Empfänger fortsetzte, wurde bereits im Zusammenhang mit den Mahlfeiern hingewiesen, die in Erinnerung an die Toten abgehalten wurden. ${ }^{30}$ Exemplarisch deutlich wird diese Verzahnung zwischen euergetischem Stifter- und Totengedenken in der Weise, in der ein Augustale aus Misenum, Q. Cominius Abascantus, in der Mitte des 2. Jh. n. Chr. sein Vermögen und seinen Nachlass zur Sicherung seiner Memoria einsetzte. ${ }^{31}$ Schon zu Lebzeiten hatte Cominius auf dem Forum von Misenum zwei Statuen errichten und anlässlich ihrer Weihung sportulae in abgestufter Höhe unter die Dekurionen, die Augustalen, die Mitglieder von Kollegien und die municipes verteilen lassen. ${ }^{32}$ Ferner stellte Cominius durch eine Stiftung sicher, dass jedes Jahr an seinem Geburtstag der städtische Rat und der populus von Misenum eine mulsatio (Weinfest) feiern sollten; durch eine weitere Stiftung wurde gewährleistet, dass auch die Augustalen an Cominius' Geburtstag Wein trinken und eine Sportelverteilung vornehmen sollten. ${ }^{33}$ Derartige Leistungen setzten sich in vergleichbarer Form auch nach Cominius' Tod fort: Cominius setzte für das Augustalenkollegium von Misenum ein Legat als Stiftungskapital aus, aus dessen Zinsen unterschiedliche Aufwendungen bestritten werden sollten: die jährliche Reinigung und Schmückung der beiden Statuen, die Cominius auf dem Forum von Misenum hatte aufstellen lassen, mit Veilchen und Rosen; die Abhaltung von Ringkämpfen an den Parentalia in der Nähe von Cominius' Kepotaph, für die Cominius die Kampfpreise und Kosten festlegte; die Schmückung seines Grabes und eine Ölspende an seine sterblichen Überreste und die Ausrichtung eines Mahls (epulari) für die Dekurionen und

Monument. Ähnlich betrachtet auch Plin., nat. 34, 17 die Totenmemoria als Ausgangspunkt der römischen Memorialkultur: excepta deinde res est a toto orbe terrarum humanissima ambitione, et in omnium municipiorum foris statuae ornamentum esse coepere propagarique memoria bominum et honores legendi aevo basibus inscribi, ne in sepulcris tantum legerentur.

30 Vgl. o., S. 61f.

31 Die im folgenden referierten Vorgänge sind aus zwei Inschriften aus dem Kollegiengebäude der Augustalen von Misenum bekannt. Sie und eine weitere Inschrift, die einen Beschluss des Augustalenkollegiums dokumentiert, Nymphidia Nomine, die Witwe des Cominius, in das Kollegium zu kooptieren, waren auf drei Seiten einer Statuenbasis eingemeißelt, die Nymphidia Nomine zu Ehren ihres Mannes errichtet hatte (für eine Ausgabe der Inschriften und einen Kommentar vgl. d'Arms 2000).

32 Die Decurionen erhielten jeweils 20, die Augustalen 12 bzw. 8, die Mitglieder von Kollegien 6 und die municipes 4 Sesterzen.

33 Ebd., 130. 
die Augustalen in der Nähe des Grabes und eines sacrificium für den Toten. Die verbleibende Restsumme sollte für die Ausbesserung des Kepotaphs verwendet werden. ${ }^{34}$

Die Stiftung, die Cominius Abascantus für die Feier seines Totengedenkens einrichtete, erscheint in mehrfacher Hinsicht als Fortsetzung einer Tätigkeit, die auch sein Handeln als Euerget zu seinen Lebzeiten bestimmt hatte: Im Zentrum des Gedenkens an Cominius standen nicht der Tod und Cominius' Status als Toter. Wie schon in den Feiern, die er jährlich anlässlich seines Geburtstages gestiftet hatte, waren es die Dekurionen und die Augustalen von Misenum, die neben der städtischen Bevölkerung auch in der testamentarischen Stiftung in besonderer Weise bedacht wurden. Ferner bildete das Totengedenken den Anlass, erneut die beiden Statuen auf dem Forum der Stadt, deren Weihung Cominius seinerzeit mit der Verteilung von Geldspenden an die Bürgerschaft verbunden hatte, zu bekränzen. Die testamentarischen Verfügungen übernahmen dieselbe Aufgabe wie die Gaben, die Cominius zu Lebzeiten verteilt hatte: Sie regelten das Verhältnis des Gebers zu den unterschiedlichen sozialen Gruppen über Gabentauschbeziehungen. Diese Fortsetzung der Euergesie „aus dem Grab heraus“ macht deutlich, dass im Totengedenken dieselben Prinzipien und Begründungen für Erinnerung wirksam waren wie zu Lebzeiten des Stifters. Die Totenmemoria hielt ein auf Gruppen bezogenes Handeln des Stifters gegenwärtig und führte diese patronalen und euergetischen Sozialbeziehungen über den Tod hinaus fort.

Das im vorigen skizzierte Bild von der antiken Stadt als einem euergetischen Handlungszusammenhang war seit der Spätantike massiven Veränderungen ausgesetzt, die mindestens einen Strukturwandel, nach Ansicht zahlreicher Forscher aber ein gänzliches Abreißen der städtischen Kultur im Übergang von der Spätantike zum Frühmittelalter signalisieren. Als Ursachen für diese Entwicklung werden in der Forschung ${ }^{35}$ vor allem zwei Faktoren hervorgehoben: zum einen eine zunehmende staatliche Durchdringung, die verstärkt seit dem 3. Jh. zu greifen begonnen und die Autonomie der lokalen euergetischen Handlungszusammenhänge untergraben habe, zum anderen ein veränderter Charakter der euergetischen Gabe selbst, die sich unter christlichem Einfluss zum karitativen Almosen gewandelt und sich nicht mehr an die Bürger, sondern an die Armen - und damit eine Bezugsgruppe, die sich rein ökonomisch und nicht politisch definierte - gerichtet habe. Beide Erklärungsansätze, die städtische Veränderungen auf einer idealtypischen Ebene in den Blick nehmen und nicht den Anspruch erheben, die Vielgestaltigkeit dieses komplexen Transformationsprozesses, der regional

$34 \quad$ Ebd., $135 f$.

35 Vgl. im einzelnen u., S. 515-518. 
unterschiedlich ablief und von einer Vielzahl wirtschaftlicher, politischer und kultureller Entwicklungen abhängig war, zu erfassen, ${ }^{36}$ stimmen dahingehend überein, dass sie den euergetischen Gabentausch als das wesentliche Strukturelement der antiken Stadt begreifen und Veränderungen im Bereich dieses Handlungszusammenhangs als das maßgebliche Kriterium für den städtischen Strukturwandel in der Spätantike auffassen. Im folgenden soll dieser Ansatz aufgenommen und um einen neuen Aspekt erweitert werden, nämlich um die Frage, inwieweit durch die Christianisierung bedingte Veränderungen der Memorialkultur Auswirkungen auf die Stadt als eine Form der sozialen Vergemeinschaftung hatten, die in elementarer Weise auf memorialen Gabentauschbeziehungen beruhte. Dabei wird deutlich werden, dass die Christianisierung ein strukturelles Veränderungspotential in sich barg, das mit einer Konzentration allein auf die caritas und die nicht städtisch definierten Bezugsgruppen karitativer Handlungen nicht adäquat erfasst werden kann. Vielmehr sind neben der Gabe und ihren Empfängern auch die memorialen Gabentauschbeziehungen zu berücksichtigen, die durch karitative Zuwendungen begründet wurden. In ihnen wurde eine spezifisch jüdischchristliche Konzeptualisierung von Erinnerung wirksam, die sich von der griechisch-römischen fundamental unterschied und den Keim zur Auflösung der antiken Stadt und der sie konstituierenden Memorialkultur in sich trug. Um diesen Zusammenhang zu verdeutlichen, sei zunächst die Forschungslage zu den oben berührten Erklärungsansätzen städtischer Transformation in der Spätantike - „Schwächung euergetischer Handlungszusammenhänge aufgrund von staatlicher Durchdringung“ und „Wandel von der Euergesie zur

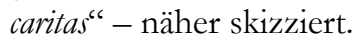

Die These, dass die zunehmende Tendenz zur Bürokratisierung und Verstaatlichung in der Spätantike zu einem Niedergang der antiken Stadt geführt habe, beruht auf der Überlegung, dass soziale Handlungszusammenhänge, wie sie durch die euergetische Praxis und die Begründung von Gabentauschbeziehungen zum Ausdruck kamen, in der Spätantike nicht mehr evident und erfahrbar gewesen seien. ${ }^{37}$ Die zunehmende Entmündigung der städtischen Oberschichten durch die kaiserliche Zentralverwaltung habe die städtischen Honoratioren zu ausführenden Organen einer Bürokratie herabgewürdigt und damit den oben skizzierten Zusammenhang eines identitätsvermittelnden Gabentauschs auf städtischer Ebene zerstört: Die öffentliche

36 Zu den einzelnen Faktoren (Verschlechterung der wirtschaftlichen Lage, Rückgang städtischer Selbstverwaltung, wachsender Außendruck durch barbarische Eroberungen, kultureller Wandel durch die zunehmende Christianisierung) vgl. zuletzt Liebeschuetz 2001, 1-25, der insbesondere mit Blick auf die ökonomischen Aspekte betont, dass sie bisher nur unzureichend erforscht und wir von einer Bilanz noch weit entfernt seien. Aus mediävistischer Perspektive vgl. die jüngste Übersicht von Wickham 2005, 591-692.

37 Zum folgenden vgl. pointiert Martin 1990, 459-462, 464f.; dens. 1994, 110-112. Zur Ausdehnung staatlicher Regelungskompetenzen in der spätantiken Gesetzgebung vgl. dens. ${ }^{31995,} 194$. 
Leistungsbereitschaft der Dekurionen wurde nicht mehr mit Blick auf die Stadt wirksam, sondern - vor allem mit Blick auf die Steuerverantwortung für den Staat in Anspruch genommen. ${ }^{38}$ An die Stelle der traditionellen städtischen Oberschichten als Wohltäter traten zunehmend Beamte der Reichsverwaltung, deren Gaben nicht mehr den Erwartungen der Gemeinde an „ihre“ Euergeten geschuldet waren, sondern den Direktiven eines abstrakten „Staates“, der erstmals in der römischen Geschichte seine Handlungskompetenzen in umfassender Weise auf die Geschicke der städtischen Gemeinden ausdehnte. ${ }^{39}$ Die Identität dieser Reichsbeamten gründete ebenso wenig auf ihrer Zugehörigkeit zur Stadt wie die der mächtigen, häufig landsässigen possessores, die den traditionellen Dekurionenstand an die Seite drängten und - teilweise in Konkurrenz auch zur staatlichen Verwaltung patronale Beziehungen zu den Städten begründeten. ${ }^{40}$ In gleicher Weise verlor auch für die Bewohner der Städte der Bürgerbegriff sein identitätsstiftendes Moment - der Städter wandelte sich vom Bürger zum Reichsbewohner. ${ }^{41}$

38 Die Verpflichtungen der Curialen zu munera wurden bereits seit der severischen Zeit zunehmend gesetzlich geregelt; seit dem 4. Jh. sind zahlreiche Kaisergesetze zu dieser Thematik überliefert. Vgl. dazu Vittinghoff 1982, 128-137, der zurecht betont, dass die staatlichen Eingriffe nicht eine Schwächung der munizipalen Autonomie, sondern im Gegenteil den Schutz der Städte und ihren Erhalt als selbstverwaltete Einheiten zum Ziel gehabt hätten, und davon ausgeht, dass die soziale Verpflichtung zur Übernahme von Leistungen einen stärkeren Zwang auf die lokalen Eliten entfaltet hätte als der äußere staatliche Druck. Für den hier interessierenden Zusammenhang ist jedoch der staatliche Regelungswille als solcher entscheidend, nicht die Frage, ob damit eine Schwächung der Städte intendiert war oder nicht.

39 Das munizipale Bauwesen unterstand der Kontrolle und Aufsicht durch die Statthalter (SchmidtHofner 2006, 244f.); insbesondere für Italien im 4. und 5. Jh. sind zahlreiche Statthalter als Bauherren in Städten belegt (vgl. Cecconi 1994, 143-151). Für Ehrungen spätantiker Statthalter durch die Städte vgl. allgemein Horster 1998.

40 Zum Verschwinden der curiae in den spätantiken Städten und zum Aufstieg einer neuen städtischen Führungsschicht von vermögenden possessores, deren Prestige und Einfluss nicht mehr auf der Zugehörigkeit zur Stadt beruhte, vgl. Liebeschuetz 2001, 104-136; zur Bedeutung dieser Entwicklungen für das Ende der antiken Stadt s. ebd. 405f. Zum Charakter des häufig von Senatoren ausgeübten Stadtpatronats vgl. Krause 1987, der dessen herrschaftssoziologische Bedeutung relativiert und es nicht als eine Form der Feudalisierung auffasst, gleichzeitig aber auch von den traditionellen euergetischen Beziehungen klar absetzt (ebd., 56f.).

41 Dieses traditionelle Bild einer sich verdichtenden Staatlichkeit in der Spätantike ist insbesondere in der letzten Zeit in zahlreichen Punkten korrigiert worden: Die spätantike Gesetzgebung sei zwar Ausdruck eines umfassenden normativen Regelungswillens, habe jedoch jenseits dieses Anspruchs keine faktische Wirkung im Sinne einer flächendeckenden staatlichen Durchdringung zur Folge gehabt (Wiemer 2006, 11-13); der Ausbau reichsbürokratischer Strukturen sei nicht erst mit der Tetrarchie, sondern bereits seit der severischen Zeit erfolgt (Eich 2005, bes. $383-$ 390); die städtische Finanzautonomie sei im 4. Jh. nicht vollständig beseitigt worden, sondern habe - wie schon in der Kaiserzeit - den Städten partielle Gestaltungsräume ermöglicht (Schmidt-Hofner 2006). Diese Beobachtungen geben Anlass, von allzu schematischen Periodisierungen im Sinne eines mit der Tetrarchie einsetzenden Strukturwandels Abstand zu nehmen und ihn stattdessen als einen „kontinuierlichen Wandlungsprozess“ zu verstehen, der 
Begleitet und verstärkt wurde dieser Vorgang von Formen der Fürsorge, die innerhalb der christlichen Gemeinden seit der apostolischen Zeit praktiziert wurden, jedoch erst seit der konstantinischen Zeit durch die Aufwertung der Kirche als semistaatliche Institution an gesamtgesellschaftlicher Bedeutung gewannen und seit dem ausgehenden 4. Jh. die Ressourcen der städtischen und Reichseliten in steigendem Maße auf sich vereinigten. ${ }^{42}$ Obwohl es sich bei den karitativen Zuwendungen ebenso wie bei den traditionellen Euergesien, an deren Stelle jene traten, um Formen der materiellen Zuwendung handelte, unterschieden sich beide Phänomene in ihren Motiven und in den Bezugsgruppen, an die sich die jeweiligen Gaben richteten, grundlegend voneinander. Während die Euergesie als eine zivische Gabe für die Bürger einer Stadt geleistet und vom Euergeten in seiner Eigenschaft als Bürger erwartet und eingefordert worden war, hatte die karitative Gabe einen anderen Bezugspunkt und einen anderen Sinn. Nicht mehr der Bürgerstatus, sondern die ökonomische Armut, die nicht notwendig an die Voraussetzung gebunden war, Bürger zu sein, bildete die Grundlage dafür, karitative Zuwendungen zu beanspruchen. Der Charakter der Gabe wandelte sich damit von einer statusvermittelnden Euergesie zu einer ökonomischen Hilfe, die rein aufgrund von materieller Bedürftigkeit geltend gemacht wurde: Die Ethik des Gebens wurde nicht „,politisch“ (durch die Zugehörigkeit zur Stadt/Polis) begründet, sondern religiös (durch das jüdisch-christliche Gebot der Armenfürsorge). ${ }^{43}$

bereits deutlich vor dem Beginn der Spätantike einsetzte; dass die staatliche Bürokratie und die kaiserliche Finanzverwaltung in der späten Kaiserzeit in zunehmendem Maße die Autonomie städtischer Honoratiorenherrschaft und Regelungskompetenzen tangierte, erscheint jedoch unbestreitbar (vgl. die abgewogene Beurteilung von Vittinghoff 1982, bes. 142-144; s. auch Schmidt-Hofner 2006, 241-248). - Für Rom selbst gelten freilich besondere Bedingungen: Im Unterschied zu den Städten im übrigen Italien lassen sich hier euergetische Leistungen der senatorischen Oberschicht für die Stadt in Form von Bauten und Spielen bis ins 6. Jh. nachweisen (B. Ward-Perkins 1984, 14-31). Begünstigt wurde dies durch den Umstand, dass die Kaiser Rom seit dem 4. Jh. nur noch sporadisch aufsuchten und der Senatorenstand dadurch in eine Position an der Spitze der Stadt einrückte, die bis dahin dem Kaiser vorbehalten gewesen war (zu dieser „Munizipalisierung“ Roms vgl. Smith 2003, bes. 149-153). Dennoch entwickelte sich auch hier kein euergetisches Verhältnis zwischen der senatorischen Elite und der plebs urbana: Man muss vielmehr davon ausgehen, dass die städtische Bevölkerung im spätantiken Rom sich um 400 durch ein hohes $\mathrm{Maß}$ an Migration aus dem Umland zusammensetzte und innerhalb der Stadt patronageartige Beziehungen einzelner Senatoren zu Gruppen wirksam blieben, die möglicherweise bereits vorher bestanden hatten; insgesamt scheint das Verhältnis der Senatoren zur plebs urbana weniger von einem euergetischen amor civicus als von großer Distanz geprägt gewesen zu sein (vgl. dazu die Bemerkungen von Purcell 1999).

42 Vgl. den Überblick von Brown 2002, 16-44 mit Verweisen auf die umfangreiche ältere Literatur.

43 Zur Bürgerbezogenheit der antiken Euergesie vgl. bereits Bolkestein 1939, 467; Patlagean 1977, 182f., die den fundamentalen Unterschied zwischen den unterschiedlichen Bezugsgrundlagen einer sozialen, am Bürgerstatus orientierten und einer ökonomischen Armut, der die kirchliche Fürsorge für die Armen galt, herausstellt (ebd., 181-196). Ähnlich Brown 1992, 89-93, der den Gegensatz zwischen caritas und Euergesie zu der Bemerkung zuspitzt, dass Arme und Bettler, die 
Die zunehmende staatliche Durchdringung und die seit dem 4. Jh. vom Staat geförderte Institutionalisierung der caritas durch die Kirchen ${ }^{44}$ wirkten demnach in der Weise zusammen, dass beide zur Auflösung der traditionellen städtischen Identität beitrugen. An die Stelle des Bürgers traten zunehmend kulturelle Modelle, die sich nicht mehr durch den lokalen Bezug auf die Stadt, sondern durch universale Verbreitung definierten: Ökonomische Armut war als grundlegendes soziales Phänomen ebenso wenig auf die Stadt begrenzt wie die Identität als Reichsbewohner, die unter dem Eindruck der zunehmenden staatlichen Durchdringung für die Bewohner der Städte wahrnehmungsbestimmend wurde.

Insbesondere die Auswirkungen der Christianisierung auf diesen Prozess sind allerdings von unterschiedlicher Seite infrage gestellt worden. Eine scharfe Abgrenzung von Euergesie und caritas sei unter soziologischen Gesichtspunkten nicht überzeugend, da im Zuge der Ablösung traditioneller Euergesien durch karitative Zuwendungen herkömmliche Formen des Gebens weitergeführt worden seien, die vergleichbare soziale Strukturen geschaffen hätten wie der Euergetismus in der kaiserzeitlichen Stadt. Für diese häufig als „christlicher Euergetismus“ bezeichnete ${ }^{45}$ Fortsetzung euergetischer Praktiken unter christlichen Vorzeichen wird zum einen auf den Charakter der Zuwendungen verwiesen: Gelder, die zuvor als Gaben an die Bürgergemeinde in städtische Feste, Speisungen und Monumente geflossen waren, seien nun zunehmend in die Errichtung und Ausstattung von Kirchenbauten und Armenfürsorgeeinrichtungen investiert worden, wo sie in ähnlicher Weise einer Allgemeinheit zugute gekommen seien und durch eine Form öffentlichen Gebens den Status des Wohltäters nun nicht mehr innerhalb der städtischen, sondern der christlichen Gemeinde begründet hätten. Auch der für die Euergesie charakteristische Umstand, dass beneficia als private Gaben von den Honoratioren der Städte geleistet wurden und nicht an die Bekleidung von Ämtern gebunden waren, findet seine Entsprechung im christlichen Bereich, da die Wohltäter nicht selten als Laien tätig wurden, was mitunter zu Konkurrenz mit den Bischöfen als den institutionellen

typischen Zielgruppen der christlichen caritas, gar nicht zur antiken Bürgerschaft gerechnet worden seien. Dies ist allerdings überzogen: Eine identitäre Abgrenzung von Bürgern und Armen wurde erst aus christlicher Perspektive formuliert, vor allem in den rhetorisch zugespitzten Bischofsdiskursen des späteren 4. Jh., die den Armen einen eigenen Platz innerhalb der Bürgerschaft zuweisen wollten (vgl. de Vinne 1995, 5-47). - Mit Blick auf das spätantike Rom wird der am Bürgerstatus, nicht an der Bedürftigkeit der Empfänger orientierte Charakter der Gaben für die plebs romana hervorgehoben von Brown 1982, bes. 125.

44 Darauf hat zuletzt Brown 2002, 26-33 aufmerksam gemacht.

45 Zum Phänomen und zur Begriffsprägung eines „christlichen Euergetismus“, um diese Entwicklung zu kennzeichnen, vgl. Février 1974, 129-135; Pietri 1984, 309f.; Caillet 1993, bes. 470; eine Bilanz bei Duval/Pietri 1997, 271f. 
Leitern der christlichen Gemeinden führte. ${ }^{46}$ Hinzu kommen personelle Kontinuitäten: Als Wohltäter in den christlichen Gemeinden traten dieselben sozialen Schichten in Erscheinung, die bis dahin die Träger euergetischer Munifizenz gewesen waren und nun in den christlichen Gemeinden durch ihre Tätigkeit patronageartige Klientelverhältnisse begründeten. ${ }^{47}$

Dasselbe ist zuletzt nicht nur für die Geber, sondern auch für die Empfänger der Gaben geltend gemacht worden. So hat Peter Brown in seiner jüngsten Studie zum Verhältnis von Armut und Formen der Autoritätsbildung in spätantiken Städten die herkömmliche Forschungsmeinung infrage gestellt, wonach die „Armen“, die das Objekt der caritas bildeten, in einem von tiefer Armut geprägten Wanderproletariat zu suchen seien, das in der Spätantike verstärkt in die Städte eingeströmt sei und dort zu einem rapiden Anwachsen der städtischen Unterschichten geführt habe. Vielmehr habe es sich vor allem um die ständig vom Absinken in die Armut bedrohten unteren Mittelschichten gehandelt, die durch die christliche Armenfürsorge verstärkt in das Blickfeld wohltätiger Initiativen gerieten. Die christliche caritas stellt nach dieser Deutung keinen Gegensatz, sondern eher eine Ergänzung der traditionellen Euergesie dar: Sie habe sich nicht primär an migrierende Fremde gerichtet, sondern an Gruppen, die traditionell die Bürgerschaft der antiken Städte ausmachten und die unter dem Eindruck des alttestamentlichen Bildes vom Armen als Hilfs- und Schützbedürftigen, der an die Gerechtigkeit eines Mächtigen appelliert, von „Bürgern“ zu „Armen“, die unter dem Schutz der Bischöfe standen, ,umdeklariert“ worden seien. ${ }^{48}$ Aus dieser Perspektive bildeten die spätantiken Städte weniger die Schauplätze eines Bruchs zwischen der antiken und der mittelalterlichen Welt, sondern eher Orte der Kontinuität, an denen unterhalb der diskursiven Ebene christlicher Umsemantisierungen traditionelle Strukturen erhalten blieben und Entwicklungen in Gang gesetzt wurden, die sich - auch aus idealtypischer Sicht - eher als graduelle Transformation denn als abrupter Wandel verstehen lassen. ${ }^{49}$

46 Vgl. Brown 1992, 95f.

47 Vgl. zuletzt Rebenich 2001, 67-73.

48 Vgl. Brown 2002, 45-73; zum nicht ökonomisch geprägten Begriff des „Armen“ in der nahöstlichen und alttestamentlichen Traditon s. ebd., 68-73. Ähnliches lässt sich übrigens auch für das frühere Mittelalter feststellen, wo pauper häufig als Gegen- und Komplementärbegriff zu potens erscheint (vgl. Sternberg 1991, 48-51, der allerdings auf die semantische Vielfalt und die Problematik hinweist, den vieldeutigen Quellenbegriff des pauper mit sozialen und ökonomischen Realitäten in Beziehung zu setzen).

49 Dass Idealtypen konstruiert werden, um Unterschiede zu profilieren, wurde bereits erwähnt (s. o., Anm. 19). Es geht also im folgenden nicht um die Frage, ob die spätantiken Städte Schauplätze von Transformationsprozessen waren - das waren sie selbstverständlich -, sondern ob sich idealtypisch relevante Konzepte wie Euergetismus und caritas, Bürger und Armer überzeugend miteinander verbinden lassen oder nicht. 
Diese Sicht auf den „christlichen Euergetismus“ und die Übernahme euergetischer und patronaler Strukturen gibt Anlass, die Problematik erneut zu überdenken. Was änderte sich mit der zunehmenden Ausbreitung einer spezifisch christlich geprägten Ethik der Gabe an dem euergetischen, den städtischen Raum gestaltenden und die städtischen Sozialbeziehungen erhaltenden System? Kam es unter den Vorzeichen eines „christlichen Euergetismus“ zu einer Umformung der antiken Stadt, in der die städtischen Armen die traditionelle Rolle der Bürger übernahmen und unter Aufrechterhaltung euergetischer und patronaler Strukturen zu Trägergruppen einer neuen städtischen Identität wurden? Oder ist es überzeugender, trotz der städtischen Verortung der Bischöfe und der Armenfürsorge, trotz personeller und struktureller Kontinuitäten euergetischer Wohltätigkeit und trotz der Errichtung von christlichen Sakral- und Funktionsbauten, die auch in materieller und monumentaler Hinsicht ein Fortexistieren zahlreicher antiker Städte gewährleisteten, die christliche caritas als einen radikalen Systemwandel zu begreifen, der die Auflösung der antiken Stadt wie auch des städtischen Raums bedingte?

Um diese Fragen zu beantworten, erscheint es sinnvoll, den Blick nicht allein auf die Begründung der Gabe als politisch oder religiös motivierte Leistung oder die sich wandelnden Bequgsgruppen euergetischer beziehungsweise karitativer Gaben zu beschränken, sondern auf den gesamten Handlungszusammenhang von Gabe und memorialer Gegengabe auszudehnen. Angesichts der Bedeutung, die der Erinnerung im antiken Euergetismus als Motor und Ziel eines ständig aktualisierten Gabentauschs zukam, stellt sich die Frage, ob die christliche Konzeptualisierung von Erinnerung in ähnlicher Weise geeignet war, einen euergetischen Handlungszusammenhang von Gabentauschbeziehungen zu begründen, oder ob durch ein spezifisch christliches Memoriakonzept Veränderungen wirksam wurden, die auch Auswirkungen auf die sozialen Beziehungen hatten, in denen sich das Wechselspiel von materieller und memorialer Gabe vollzog. Es gilt dafür zunächst, einige grundlegende Voraussetzungen des frühchristlichen Verständnisses von Erinnerung und Gedenken zu skizzieren, um in einem zweiten Schritt die sozialen Konsequenzen zu verdeutlichen, die daraus für die spätantike Stadt erwuchsen.

Ähnlich wie in der römischen Welt waren auch im frühen Christentum Erinnerung und Kommemoration, wie sie im Totengedenken zutage traten, Ausdruck eines weit umfassenderen Zusammenhangs: Memoria war eine soziale Gabe, die nicht nur das Verhältnis zwischen Lebenden und Toten, sondern in elementarer Weise die Beziehungen der Lebenden untereinander bestimmte. Als Beispiel kann ein Brief des Bischofs Cyprian von Karthago dienen, den dieser um die Mitte der 250er Jahre an acht numidische Bischöfe richtete. Den Anlass des Schreibens bildete die Übersendung einer beträchtliche Geldsumme von 100.000 Sesterzen, die Cyprian in Karthago 
und weiteren Gemeinden gesammelt hatte, um den Freikauf von numidischen Christen zu ermöglichen, die in die Hände von Räubern gefallen waren. Cyprian legte dem Brief auch ein - nicht überliefertes - namentliches Verzeichnis der Spender bei, damit die Empfänger des Geldes derjenigen gedachten, die diese Gaben aufgebracht hatten:

„Damit ihr aber unserer Brüder und Schwestern, die zu diesem so notwendigen Werk bereitwillig und gerne beigetragen haben, wie sie das stets tun werden, in euren Gebeten auch gedenken (in mente habere) und ihnen bei den Opfern und Gebeten euch dankbar erweisen könnt, füge ich unten ihre Namen einzeln bei. Aber auch die unserer Amtsgenossen und Bischöfe führe ich namentlich auf, die gleichfalls bei ihrer Anwesenheit in ihrem eigenen und ihres Volkes Namen nach Kräften beigesteuert haben, und außer unserer eigenen Spende nenne und schicke ich auch ihr Scherflein; denn wie der Glaube und die Liebe es erheischt, müsst ihr bei euren Gebeten und Andachten ihrer aller gedenken (in orationibus et precibus meminisse)." 50

Auf den ersten Blick scheint sich hier eine strukturelle Gemeinsamkeit zwischen dieser karitativen Fürsorgetätigkeit und euergetischen Formen der Zuwendung abzuzeichnen. Abgesehen davon, dass in Cyprians Brief das „Werk“ der Gabe religiös und nicht politisch begründet wurde, brachte es den karitativen Geber und den armen Empfänger in ein ähnliches Verhältnis zueinander wie den Euergeten und den Bürger: Die durch Cyprian vermittelte Gabe sollte aufseiten der Empfänger durch eine Gegengabe beantwortet werden, die in der Kommemoration der karitativen Wohltäter bestand. In rein struktureller Hinsicht, unabhängig von der Motivation der Gabe und von den Gruppen, die sie erhielten, lässt sich die caritas daher ebenso wie die Euergesie als ein Gabentausch auf kommemorialer Grundlage verstehen: In beiden Fällen bildete das wechselseitige Geben die Grundlage einer sozialen Beziehung zwischen Geber und Empfänger, und ähnlich wie im antiken Euergetismus war auch bei karitativen Akten wie dem Freikauf der numidischen Gefangenen die Erinnerung eine Gegengabe, mit der materielle Leistungen beantwortet wurden.

Bei allen strukturellen Parallelen tritt in dem Brief Cyprians jedoch eine spezifische Bedeutung von Erinnerung zutage, die auf eine fundamentale Differenz zwischen euergetischer und karitativer Memoria verweist: Das Erinnern der Wohltäter erfolgte durch ein Gebet, dadurch, dass man den Geber und seine Leistung bei Gott in Erinnerung rief. Diese Bedeutung von Erinnern und Erinnerung als einer kommemorierenden Fürbitte war im

50 Cypr., epist. 62, 4, 2: ut autem fratres nostros ac sorores, qui ad hoc opus necessarium tam prompte ac libenter operati sunt, ut semper operentur, in mente habeatis in orationibus vestris et eis vicem boni operis in sacrificiis et precibus repraesentetis, sudidi nomina singulorum, sed et collegarum quoque et consacerdotum nostrorum, qui et ipsi cum praesentes essent et suo et plebis suae nomine quaedam pro viribus contulerunt, nomina addidi et praeter quantitatem propriam nostram eorum quoque summulas significavi et misi, quorum omnium secundum quod fides et caritas exigunt in orationibus et precibus vestris meminisse debetis. Zur Datierung des Schreibens vgl. Clark, in: Cypriani Epistularium (CC 3D), 691f. 
christlichen Sprachgebrauch tief verankert und führte zu einer folgenreichen semantischen Umprägung des Begriffs. Bereits die paulinischen Briefe geben davon ein ausführliches Zeugnis, ${ }^{51}$ und vor allem die spätere Epistolographie $^{52}$ und die Liturgie ${ }^{53}$ transportierten diesen Wortgebrauch durch die gesamte Antike hindurch bis ins Mittelalter: Erinnern bedeutete „im Gebet vor Gott nennen". 54

Die kulturspezifischen Differenzen zur antiken Memorialkultur, die aus dieser christlichen Konzeptualisierung von Erinnerung erwuchsen, erschließen sich erst, wenn man den weiteren Zusammenhang und die jüdischen Wurzeln berücksichtigt, auf denen die christliche Vorstellung von der Memoria als Gebetsleistung beruhte. Im Alten Testament bildet das Erinnern - hebräisch z $k r$ - einen Begriff, der für das Verhältnis Gottes zu den Menschen von zentraler Bedeutung ist: Die Zuwendung und Hilfe Gottes für sein Volk sind Ausdruck seines Gedenkens, das nicht als ein rein retrospektives Erinnern, sondern eher im Sinne eines gegenwartsbezogenen „eingedenk sein/denken an“ aufzufassen ist, und das einen heilsgeschichtlich begründeten Handlungsbezug zwischen der Gottheit und ihrem Verehrer impliziert, dessen ganze Existenz an das Gedenken Gottes gebunden ist. ${ }^{55}$ In dieser fundamentalen Bedeutung des Erinnerns im Gott-Mensch-Bezug liegen auch die Ansätze für das seit Paulus fassbare christliche Gebetsgedenken der Fürbitte: Man tat derjenigen Person, der die kommemo-

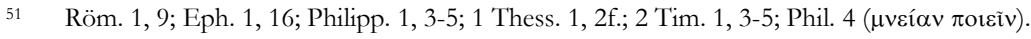

52 Als abschließende Formel an den Adressaten mit der Bitte, des Schreibers zu gedenken, bei Ign., Magn. 14; Trall. 13, 1; Rom. 9, 1; Eph. 21, 1. Cypr., epist. 10, 5, 3; 12, 2, 2; 14, 4; 15, 4; 16, 4, 2; 17 , 3, 2; 18, 2, 2; 19, 2, 3; 26, 4; epist. Silvan. (CC 3, 660). Vgl. ferner Aug., epist. 29, 12; 130, 31. Für formale - Parallelen zum traditionellen Briefstil vgl. Bastiaensen 1964, 11. Für weitere Belege für „Erinnern“ in der Bedeutung als Gebetsgedenken vgl. Cypr., hab. virg. 24; dens., epist. 60, 5 und besonders Aug., cur. mort. 4, 6 zur Verbindung von Heiligen- und Gebetsgedenken: Graeci $\mu \nu \eta \mu \varepsilon i o v ~ v o c a n t$, quod nos memoriam seu monumentum appellamus, quoniam lingua eorum memoria ipsa, qua meminimus, $\mu v \eta \dot{\mu \eta}$ dicitur. cum itaque recolit animus, ubi sepultum sit carissimi corpus et occurit locus nomine martyris venerabilis, eidem martyri animam dilectam commendat recordantis et precantis affectus.

53 Vgl. z. B. Const. App. 8, 10, 18 u. 13, 6. Das Gebet, in dem der Märtyrer Polykarp vor seinem Martyrium der Kirche ,gedenkt“ (Martyrium Polycarpi 8, 1) geht vermutlich auf ein liturgisches Gebetsgedenken zurück (vgl. Tripp 1990). Zum Niederschlag in inschriftlichen Zeugnissen s. o., S. 43.

54 Dies die Definition von Kretschmar 1977, 104.

$55 \mathrm{Zu}$ den im Gedenken Gottes wirksamen Handlungsbeziehungen vgl. exemplarisch Ps. 88, 6: „Unter Toten muss ich wohnen, gleich Erschlagenen, die im Grabe liegen, an die du nicht mehr denkst und die abgeschnitten sind von deiner Hand.“ Vgl. auch die Bemerkungen von Childs 1962, 33: „There are no examples where this reflection does not isssue in the objective intervention toward that which was remembered. Memory is not identical with the action, but it is never divorced from it“ und Schottroff 21967, 201: „Zkr als Begriff für die Beziehung Gottes zum Menschen bezeichnet keinen bloß gedächtnismäßigen Bezug, sondern ein tathaftes Eingehen der Gottheit auf den Menschen, der sich in Not befindet.“ Für das Erinnern Gottes im Alten Testament vgl. allgemein Childs 1962, 31-44; Schottroff 21967, 183-243. 
rierende Fürsprache galt, im Gebet Erwähnung und rief sie dadurch Gott in Erinnerung. ${ }^{56}$

Für den hier interessierenden Zusammenhang ist die Genese der alttestamentlichen Verheißungs- und Bundestheologie, die das Erinnern und Gedenken zu einer zentralen Achse im Gott-Mensch-Bezug machte, ${ }^{57}$ von nachrangiger Bedeutung. Entscheidend ist der Umstand als solcher, dass in der jüdischen Tradition das Gedenken eine Handlungsbeziehung zwischen Gott und seinem Volk begründete. Diese - trotz der spezifischen Voraussetzungen der jüdischen Heilsgeschichte - nicht nur im antiken Judentum, sondern im gesamten semitischen Sprachraum des Vorderen Orients verbreitete Vorstellung findet im griechisch-römischen Kulturkreis keine Entsprechung: Sie begründete eine kultursperifische Semantik des Erinnerns, das nicht allein als ein sozialer, zwischen Menschen praktizierter Vorgang sondern auch in der Relation zwischen Mensch und Gottheit wirksam wurde. Die damit verbundene semantische Differenz erhellt aus griechischen Gedenkinschriften und -graffiti des östlichen Mittelmeerraums, bei denen hinsichtlich der Verwendung des Verbums „erinnern“ charakteristische Unterschiede zutage treten: Während in Syrien, Palästina und Arabien durch die Wendung „des NN möge gedacht werden“ die Vorstellung artikuliert wird, dass eine Person Aufnahme in das Gedenken einer Gottheit finden soll, ist für Griechenland eine Formel („NN gedenkt des NN“) typisch, in der das Erinnern als ein sozialer Vorgang erscheint, der für das Verhältnis zwischen Menschen und Göttern keine Bedeutung hat. ${ }^{58}$

56 Diese enge Verwandtschaft von Erinnern und Erwähnen kommt im Hebräischen dadurch zum Ausdruck, dass bizkir, das Hiphil (der Kausativstamm) von $z k r$, die Bedeutung „erwähnen, nennen, aussprechen“ hat: Aus der Grundbedeutung ,gedenken“, wurde das kausative Hiphil

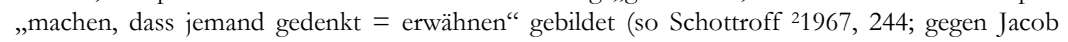
1897, 48f., 69-76; wenig überzeugend ist demgegenüber de Boer 1962, 63f., der die Hiphilform bizkir „nennen, erwähnen“ als die Grundbedeutung von zker erweisen möchte [vgl. auch die Kritik von Childs 1962, 12, Anm. 3 und Schottroff 21967, 8 mit Anm. 4]). Diese semantische Bezogenheit von „gedenken“ und „aussprechen, damit jemand gedenkt" ist auch als der entscheidende Ausgangspunkt für das christliche Gebetsgedenken anzusehen. Vgl. Fee 1995, 78,

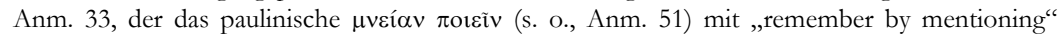
wiedergibt; zur Verwurzelung der Wendung in der jüdischen Tradition s. auch Michel 1942, 682 (,überall ist die Grundlage des alttestamentlichen zakar bzw. zeker spürbar"). Spicq 1982, $466 f$.

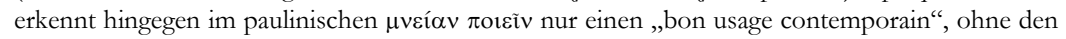
jüdischen Hintergrund in Erwägung zu ziehen, und reduziert die Bedeutung der Wendung auf ein reines „erwähnen“.

57 Dem Gedenken Gottes an Israel entsprach ein Gedenken Israels an Gott, das die zurückliegenden Taten Jahwes und das Heilshandeln Gottes an seinem Volk - vor allem im Gebet - vergegenwärtigte: Im Gott-Mensch-Bezug war auf diese Weise ein beiderseitiges Erinnern an die Heilsgeschichte und ihr Fortwirken in der Gegenwart wirksam (vgl. Childs 1962, 45-65 und - zu den historischen Entwicklungsstufen - Boccaccini 1985).

58 Vgl. Rehm 1941, der zwischen einem „östlichen“ ( $\mu \nu \eta \sigma \theta \eta ̣$ ó $\delta \varepsilon i ̃ v \alpha-$ der Konjunktiv ist als

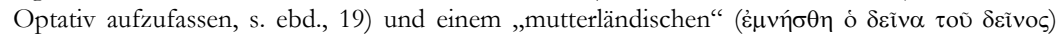
Typus differenziert; zur geographischen Verbreitung der beiden Typen vgl. ebd. 8, 20. Das 
Für die Frage nach der Memoria und dem Gebetsgedenken im frühen Christentum ist diese kulturspezifische Prägung des Erinnerungsbegriffs im semitisch-jüdischen Kulturraum fundamental. Die Ursprünge des Christentums lagen in einer Religion, in der Erinnerung als religiöses Phänomen eine zentrale Achse nicht zwischen den Menschen, sondern zwischen Gott und den Menschen begründete: ${ }^{59}$ Das fürbittende „Nennen vor Gott“ ließ dessen Erinnerung mit Blick auf denjenigen, der die Fürbitte veranlasst hatte, wirksam werden und machte Gott damit zum wesentlichen Akteur und zu demjenigen, der durch die Gabe seines Gedenkens einen Gabentausch mit

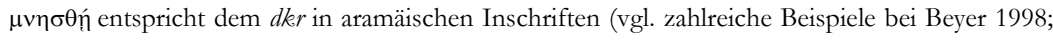
Schottroff 21967, 12-106), was auf einen semitischen Hintergrund der Vorstellung verweist. Problematisch ist die Beurteilung der Erinnerungsbezüge im hellenistischen Ägypten, wo sich an viel besuchten Sehenswürdigkeiten und Pilgerorten wie dem Isistempel von Philae oder dem Memnonkoloss in Theben zahlreiche Besucher durch tituli memoriales verewigt haben. Neben den beiden Typen von $\mathrm{MNH} \Sigma \Theta \mathrm{H}-$ Formularen begegnet in den dortigen Graffiti auch häufig die charakteristische Wendung „NN hat das $\pi \rho \circ \sigma \kappa u ́ v \eta \mu \alpha$ von NN bei der Gottheit NN gemacht“ oder ,geschrieben“ (mit Varianten). Ausgehend von der letzten Bedeutung hat Geraci 1971, bes. 16f. die These aufgestellt, das Proskynema sei mit dem Graffito selbst identisch, und die Bedeutung der Proskynemata davon ausgehend zu bestimmen gesucht: Der eigentliche Gegen-

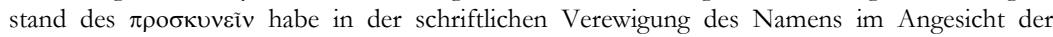
Gottheit bestanden, was die Herstellung einer ähnlichen Erinnerungsbeziehung zwischen Verehrer und Gottheit implizieren würde, wie sie aus dem semitischen Raum bekannt ist. Durch das Anbringen einer Inschrift soll eine dauerhafte personale Beziehung begründet werden, die den Verehrer vor der Gottheit ständig gegenwärtig und erinnerbar hält. Dagegen plädiert Guarducci 1974 (a), 198-206 dafür, dass die Proskynemata-Graffiti zwar Handlungen verbalisieren, durch die die Besucher ihre Verehrung zum Ausdruck brachten, jedoch nicht mit dem eigentlichen Akt der Verehrung gleichzusetzen sind; unentschieden Bernard 1983, 676f. Ob sich der „kommemoriale Sinn" der Graffiti in einem - bezüglich der Adressaten nicht näher bestimmbaren Willen erschöpfte, einer als wichtig empfundenen Handlung dadurch besonderen Nachdruck zu verleihen, dass man sie aufzeichnete, oder ob er darin bestand, der Gottheit einen Namen gegenwärtig und in Erinnerung zu halten, ist schwer zu entscheiden. Auf letzteres deuten jedoch

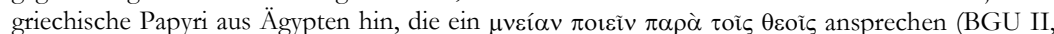
632 mit Ewald 1905, 95; vgl. auch ebd., 270; Koskenniemi 1956, 146f.).

59 Zur Provenienz des christlichen Gebetsrufs $\mu \nu \eta ́ \sigma \vartheta \eta \tau \imath$, кú vgl. Clerici 1966, 48-64. Die Bitte um das Gedenken Gottes ist in den spätantiken Liturgiefamilien unterschiedlich stark ausgeprägt: Die Anaphoragebete der Liturgien westsyrischer Provenienz (Basileios- und Jakobusliturgie) kleiden in stärkerem Maße als die ägyptische Markusliturgie die Bitte um Hilfe Gottes in die Form eines göttlichen Gedenkens: Die Anaphora der Basileiosliturgie enthält in ihrer Kurzfassung sechsmal den Gebetsanruf $\mu v \eta ́ \sigma \theta \eta \tau$

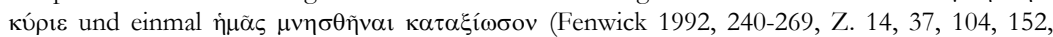
191, 241, 352f.), in der Langfassung finden sich noch neun weitere Belege (ebd., Z. 28, 55, 69, 221, 234, 256, 294, 325, 533). Die anaphorischen Fürbitten der ägyptischen Markusliturgie wählen hingegen für die Form der Gebetsanliegen nur zweimal die Semantik eines göttlichen „Gedenkens“ (vgl. die Urform bei Andrieu/Collomp 1928, 500, Z. 19; 501, Z. 11; Fürbitten mit dem verstärkten Gebrauch von $\mu \nu \eta ́ \sigma \theta \eta \tau \imath-F o r m e l n$ sind als sekundäre Erweiterungen aus den westsyrischen Liturgien anzusehen [vgl. Engberding 1964, 433-441; Text bei Cuming 1988, 22 37]). Die regionale Differenzierung kann hier nicht weiter vertieft werden; entscheidend ist, dass sich das $\mu \nu \eta ́ \sigma \vartheta \eta \tau \imath, \kappa u ́ \rho \iota \varepsilon$ in allen Liturgiefamilien erhalten hat (für den Westen vgl. exemplarisch das memento, Domine im römischen Messkanon [s. o., S. 422]). 
dem karitativen Wohltäter vollzog. Anders als es der oben zitierte Brief Cyprians auf den ersten Blick suggerieret, war die soziale Gabe der Memoria im christlichen Gebetsgedenken demnach nicht einfach Teil eines Gabentauschs, der - analog zum Euergetismus - durch ein wechselseitiges Geben zwischen Wohltäter und Empfänger in Gang gehalten wurde. Dies wird deutlich, wenn man ein weiteres antikes Zeugnis heranzieht, das die Differenzen zwischen euergetischem und karitativem Gabentausch klarer reflektiert. Etwa zur selben Zeit, in der Cominius Abascantus in Misenum durch seine Stiftungen dem Selbstverständnis und den Grundlagen der kaiserzeitlichen Memorialkultur beredten Ausdruck verlieh, entstand der „Hirte des Hermas", eine etwa um 140 n. Chr., möglicherweise in Rom verfasste Schrift. ${ }^{60}$ Ihr Verfasser nahm das Bild eines Weinstocks, der sich an einer Ulme emporrankt, zum Anlass, um seine Vorstellung von den Beziehungen zwischen Reich und Arm und von dem Gabentausch, der sich zwischen beiden innerhalb der Gemeinde vollzog, zu formulieren:

„Der Weinstock bringt Frucht, die Ulme dagegen ist unfruchtbares Holz. Aber wenn der Weinstock nicht an der Ulme hochrankt, kann er nicht viel Frucht bringen, weil er am Boden liegt; und was er an Frucht bringt, ist faul, weil er nicht an der Ulme hängt. Wenn der Weinstock nun an der Ulme hochgebunden ist, dann bringt er aus eigener Kraft Frucht und mit Hilfe der Ulme... Dieses Gleichnis bezieht sich also auf die Diener Gottes, auf Arm und Reich... Der Reiche hat zwar seinen Besitz, in seinem Verhältnis zum Herrn ist er aber arm, weil er völlig mit seinem Reichtum beschäftigt ist, und sein Bitt- und Lobgebet zum Herrn ist äußerst dürftig, und wenn er es überhaupt betet, ist es schwach, dürftig und ohne jede Kraft. Der Reiche stützt sich nun auf den Armen und versorgt ihn mit dem Lebensnotwendigen, und zwar in dem Glauben, dass er seinen Lohn von Gott wird bekommen können, wenn er für den Armen etwas getan hat; der Arme ist ja reich an seinem Bitt- und Lobgebet, und sein Gebet hat großen Einfluss bei Gott. So versorgt der Reiche den Armen ohne Zögern mit allem. Der Arme seinerseits, der von dem Reichen versorgt wird, betet zu Gott voll Dank gegen ihn - für den, der ihm mitgibt. Dieser wieder bemüht sich eifrig noch und noch um den Armen, damit es ihm im Leben an nichts fehlt... Beide zusammen erbringen also das Werk. Der Arme wirkt mit seinem Gebet, worin sein Reichtum liegt; er hat es vom Herrn bekommen, er gibt es dem Herrn zurück zugunsten dessen, der ihn versorgt. Und genauso gibt der Reiche seinen Reichtum, den er vom Herrn bekam, ohne Zögern dem Armen. Und dieses Tun wiegt viel und ist angenommen von Gott, weil er den Sinn des Reichtums begriffen hat und mit den Gaben des Herrn etwas für den Armen tat und den Dienst recht ausgeführt hat."61

60 Die Redaktion der Schrift, in der ältere Elemente verarbeitet wurden, wird um $140 \mathrm{n}$. Chr. angesetzt, vgl. Brox 1991, 13-33.

61 Herm., sim. 2, 3-7. Der Vollzug dieses Gabentauschs wird angedeutet in: Herm., sim. 5, 2, 10 (Speisung) und 5, 3, 7 (soziales Fasten: Der Betrag, der durch das Fasten eingespart wird, wird an Witwen oder Waisen gespendet, „damit der Beschenkte satt wird und für dich zum Herrn betet."). 
Diese Bemerkungen zum Verhältnis vom Armen und Reichen verdeutlichen, dass das christliche Gebetsgedenken strukturell als Teil eines erweiterten Gabentauschs aufgefasst werden muss, der neben dem Geber und dem Empfänger der materiellen Gabe Gott als dritten Beteiligten einbezieht: Gott gibt dem Reichen, der wiederum den Armen mit Gütern versorgt, damit er den Reichen in sein Dankgebet für Gottes Gaben mit einschließt. Dieser an Gott gerichtete Dank hat zur Folge, dass Gott den Menschen auch weiterhin seine Wohltaten zukommen lässt und damit den Kreislauf der Gabe erneut in Gang setzt. Stark schematisiert lässt sich die Grundstruktur dieses Systems im Vergleich zum Euergetismus in folgender Weise als Modell darstellen:

Euergetischer Gabentausch

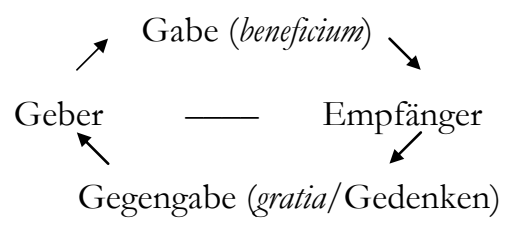

Christlich-karitativer Gabentausch

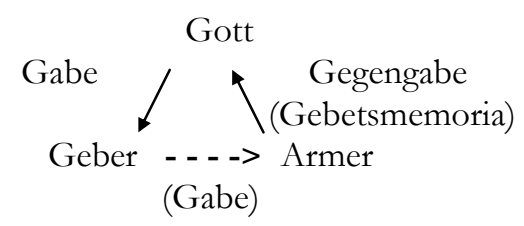

Dieser dreigliedrige Gabentausch, der im „Hirten des Hermas“ besonders klar formuliert ist, aber auch in weiteren Zeugnissen als die Grundlage einer christlich konzeptualisierten Wechselwirkung zwischen Gabe und Gebetsgedenken erkennbar wird, ${ }^{62}$ unterscheidet sich in zentralen Punkten vom traditionellen euergetischen und patronalen Gabentausch antiker Gesellschaften. Vor allem zwei Aspekte dieser Differenz sind hervorzuheben.

1. Während im Euergetismus Gabe und Gegengabe die ausschließliche Angelegenheit einer zwischen Menschen bestehenden Beziehung waren, dehnte der christliche Gabentausch diesen Handlungszusammenhang aus, indem er Gott als Geber und als Empfänger von Gaben mit einbezog: Die Relation zwischen göttlicher und menschlicher Welt wurde ein entscheidender Teil des durch Tauschbeziehungen konstituierten Systems. Dieses Gabentauschverhältnis löste die weltimmanenten, zwischen Menschen bestehenden Handlungsbeziehungen zwar nicht auf - der Reiche versorgte

62 Vgl. für die Mitte des 3. Jh. Cypr., eleem. 9: „Indem sich die Danksagung der Armen für unsere Almosen und guten Werke in dem Gebet der Armen an Gott wendet, häuft sich infolge der Wiedervergeltung Gottes das Vermögen des Wohltätigen immer mehr an. " Für die spätantike Entwicklung vgl. Duval/Pietri 1997, 389-392, die, ausgehend von spätantiken christlichen Stifterinschriften und Äußerungen Gregors I. (590-604), eine „relation triangulaire“ der Gabe zwischen Gott, dem „christlichen Euergeten“ und den Armen ausmachen. 
den Armen -, es schwächte sie jedoch entscheidend, denn das Zentrum dieses dreigliedrigen christlichen Gabentausches war nicht die Verbindung zwischen dem Armen und dem Reichen, sondern die vertikale Achse zwischen der göttlichen und der menschlichen Welt. Die Gegengabe, das Gebetsgedenken des Armen, beantwortete nicht die Gabe des Reichen, sondern galt Gott als dem eigentlichen Urheber der Gabe. Auch die Verpflichtung des Reichen zur Gabe an den Armen erwuchs nicht aus dem sozialen Verhältnis, das zwischen ihm und dem Armen bestand, sondern aus einer Verpflichtung Gott gegenüber: Der Reiche gab dem Armen, um auf diese Weise Gott die ihm gebührende Gegengabe des Lobs zukommen zu lassen.

2. Der Gabentausch zwischen dem Geber und dem Armen musste als solcher nicht sozial erfahrbar sein, da das entscheidende Gewicht auf der vertikalen Achse, der Relation zwischen göttlicher und menschlicher Welt, lag. Wann und wo sich das Gebetsgedenken als Gegengabe vollzog, war prinzipiell von sekundärer Bedeutung: Die Handlungsbeziehungen auf der horizontalen Ebene des christlichen Gabentauschmodells waren nicht an einen bestimmten räumlichen oder zeitlichen Kontext gebunden. Dadurch, dass nach christlicher Vorstellung Lebende und Tote in eine umfassende Handlungsgemeinschaft integriert waren, ${ }^{63}$ konnten die in dem Schema aufgeführten Beziehungen sich sogar bis über die Grenze des Todes hinweg erstrecken - beispielsweise dadurch, dass das Gebet des Armen für den Geber wirksam blieb, auch wenn dieser bereits verstorben war.

Die Unterschiede zwischen dieser Konzeption und dem euergetischen Gabentausch liegen auf der Hand. Wie oben ausgeführt, war der euergetische Gabentausch nicht einfach in dem Sinne sozial, dass er sich zwischen Menschen vollzog. Entscheidend war vielmehr, dass er auch weltimmanent und sozial begründet und generiert wurde: Leistung und Gegengabe gingen aus den sozialen Verpflichtungen, die gegenüber einer Gruppe - der städtischen Gemeinde - bestanden, hervor. Dieser gruppenstabilisierende Zusammenhang war dem christlichen Gabentauschmodell für beide Seiten, den reichen Geber und den armen Empfänger, nicht mehr gegeben, da der ultimative Bezugspunkt des Gabentauschs für beide Beteiligten Gott war. Die Erfahrbarkeit des Wechselspiels von Gabe und Gegengabe, die als ein wesentlicher Motor des euergetischen Gabentauschs fungierte, war für diesen „vertikalen“ Gabentausch von nachrangiger Bedeutung - eine potentielle Schwächung von innerweltlich erfahrbaren Handlungszusammenhängen, die durch die Trans-

63 S. o., S. $43-55$. 
zendierung der Kommunikationsbeziehungen und ihre Ausdehnung auf die Toten als eigenständige Handlungssubjekte noch zusätzlich verstärkt wurde.

Im folgenden soll skizzenhaft umrissen werden, welche grundlegenden historischen Ausprägungen dieses im vorigen in stark abstrahierender Form präsentierte und historisch nicht modifizierte Modell eines dreigliedrigen Gabentauschs erfuhr, und in welcher Weise die strukturellen Eigenheiten der christlichen Memorialkultur geschichtliche Gestalt gewannen. Auch wenn dabei nur die Grundlinien der historischen Entwicklung in den Blick genommen werden können, wird dennoch deutlich werden, dass in der christlichen Konzeptualisierung von Gabentauschbeziehungen ein Veränderungspotential angelegt war, dessen Konsequenzen elementare Auswirkungen auf die Entwicklung der antiken Stadt hatten.

Als Ausgangspunkt kann erneut das Gleichnis aus dem „Hirten des Hermas“ dienen. Die hohe Wertschätzung, die Hermas in der Mitte des 2. Jh. n. Chr. dem Armen und dem Wert seines Gebetes entgegenbrachte, wurzelte in einer spezifisch jüdischen Armenfrömmigkeit, die dem Armen eine besondere Gottesnähe zuwies ${ }^{64}$ und seinem Gebet die Erhörung durch Gott zusicherte. ${ }^{65}$ Diese Vorstellung äußerte sich in den christlichen Gemeinden vor allem im Gebetsdienst der Witwen, die in der früchristlichen Literatur häufig in Verbindung mit der Fürbitte erscheinen und geradezu als Spezialisten eines memorialen Gabentauschs bezeichnet werden können: Als „Altar Gottes“ nahmen sie die karitativen Gaben entgegen und beantworteten sie durch Gebete für deren Spender. ${ }^{66}$

Diese Sicht der frühen Kirche auf die Armen und das für das Almosen geleistete Gebet ${ }^{67}$ änderte sich jedoch unter dem Eindruck der zunehmenden Konversionen, die spätestens während des 4. Jh. große Teile der Eliten und der Bevölkerung der Städte erfassten. Dass die Armen gegenüber den reichen Gebern durch eine adäquate Gegengabe tätig werden konnten, war unter den Prämissen traditioneller Gabentauschmodalitäten nur schwer vorstellbar:

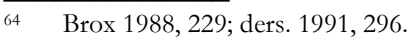

65 Ecclus. 35, 21.

66 Zur Witwe als Altar vgl. Polyc., Philipp. 4, 3 mit der Interpretation von Gryson 1972, 36; vgl. auch Osiek 1983, 166f. Der Gebetsdienst der Witwen wird ausführlich in der syrischen Didaskalie und - zum Teil von ihr abhängig - den apostolischen Konstitutionen thematisiert; vgl. u. a. Didasc. 15 (davon abhängig const. app. 3, 5, 2); Didasc. 14 (davon abhängig const. app. 3, 4, 3). Zum Gebet der Witwe als Gegengabe für materielle Versorgung in der syrischen Didaskalie vgl. Schöllgen 1998, 155-161. Für die apostolischen Konstitutionen vgl. außerdem const. app. 3, 1, 5. 7, 5; ferner 3, 13, 1 (Beispiel für ein Dankgebet einer Witwe); 3, 14, 1 (Witwe als Altar Gottes).

${ }_{67}$ Den bereits aufgeführten Zeugnissen lassen sich weitere zur Seite stellen: Im 1. Klemensbrief (Ende des 1. Jh.) wird eine ähnliche Beziehung zwischen Reichem und Armem erkennbar wie im „Hirten des Hermas“: „Der Reiche soll den Armen unterstützen, der Arme aber soll Gott dafür danken, dass er ihm (jemanden) gegeben hat, durch den seinem Mangel abgeholfen wird“ (1 Clem. 38, 2). Vgl. für das ausgehende 2. Jh. auch Clem., q. d. s. 34, 2 f. 
Während der Dank der Bürger für ihre Euergeten deren Leistung für die Stadt honorierte und als eine ehrende Auszeichnung verstanden wurde, waren die Armen als soziale Gruppe nicht in der Lage, durch ihren Dank Status zu vermitteln. Ambrosius artikulierte diese Haltung gegenüber den Armen, indem er den besonderen Wert der Gabe an sie damit begründete, dass man von ihnen keine Gegengabe erwarten könne:

„Was aber nützte dir die Begünstigung eines Reichen? Geschieht es, weil er seinem Gönner eher lohnt? Nur zu oft gilt ja denen unsere Gunst, von denen wir eine Vergeltung derselben erwarten. Um so mehr aber gebührt es sich, uns des Schwachen und Bedürftigen anzunehmen, indem wir uns statt vom Armen, der dazu nicht in der Lage ist, vom Herrn Jesus den Lohn erhoffen... Denn Reiche - den Anschein weckt es - bittet man zu Gaste, damit auch sie uns hinwiederum zu Gaste laden: Arme, die nicht in der Lage sind, für das Empfangene eine Gegenleistung zu bieten, machen uns den Herrn zum Vergelter, der sich als Bürgen für den Armen erboten hat. “68

Ambrosius deutet hier einen Handlungszusammenhang an, der von den antiken christlichen Autoren häufig geäußert wurde: Indem man dem Armen gab, gab man Christus und machte sich ihn damit direkt zum Schuldner. ${ }^{69}$ Dieser Gabentausch wurde zwar noch durch den Armen vermittelt, vollzog sich jedoch zwischen Gott und dem Geber. ${ }^{70}$ Die Armen wurden dadurch auf den Status von passiven Almosenempfängern reduziert, ${ }^{71}$ denen - anders

68 Ambr., off. 2, 126: quid autem tibi prodest favere diviti? an quia citius amantem remuneratur? his enim favemus frequentis a quibus referendae speramus gratiae. sed eo magis infirmo et inopi nos studere convenit quia pro eo qui non habet remunerationem speramus a Domino Iesu... divites enim rogari videntur ut ipsi quoque nobis reddant convivium; pauperes quia non babent quod restituant, cum acceperint, remuneratorem nobis faciunt Dominum, qui se pro paupere obligandum obtulit.

69 Zu dieser auf Prov. 17, 19 beruhenden Vorstellung vgl. Ambr., off. 1, 11, 39: Der Arme, der die Gabe des Reichen empfängt, macht Gott zu einem debitor salutis, denn ,am Tag des Gerichts wird er (der Geber) Heil finden vom Herrn, indem er ihn zum Schuldner seines Erbarmens haben wird" (in die iudicii habebit salutem a domino, quem habebit suae debitorem misericordiae). Ambr., Nab. 7, 36: bona sunt, si pauperi largiaris, in quo tibi debitorem deum quadam pietatis faeneratione constituas; Ebd., 14, 59: (der Arme) facit tibi debitorem patrem deum ... facit tibi debitorem filium. Quod enim unicuique minimorum conlatum est sibi dicit esse conlatum; ähnlich 16, 67: reddite in paupere, in egeno solvite, in illo inope faenerate, quem placare propter flagitia vestra aliter non potestis. quem ultorem timetis facite debitorem. $\mathrm{Zu}$ Gott als Schuldner vgl. ferner Ambr., Tob. 16, 55. Bei Leo I., serm. 17, 2 wird der karitative Geber zum Gläubiger Gottes. Für das 3. Jh. vgl. Cypr., eleem.: Man speist Christus im Armen (c. 12), und wer sich eines Armen erbarmt, macht sich dadurch Gott zum Schuldner (debitor) (c. 15). Der eigentliche Empfänger der Gaben ist Christus (c. 16): In den Armen wird Christus gekleidet und gespeist und verspricht den Wohltätigen das ewige Leben (c. 22-24). Für den Osten vgl. u. a. Gr. Naz., paup. 36 (Gott als Schuldner). Zur Vorstellung, dass im Armen Christus gespeist wird und man sich dadurch Gott zum Schuldner macht, vgl. weitere Belege bei Ramsey 1982, 226-229; de Vinne 1995, 77, Anm. 91; Finn 2006, 183f. In denselben Zusammenhang gehört auch die häufig artikulierte Vorstellung einer „Sohnesquote für Christus“, womit ein bestimmter für die Kirche und die Armen bestimmter Erbteil bezeichnet wurde (vgl. Bruck 1956, bes. 76-104 zur Verbreitung der Vorstellung im lateinischen Westen um 400).

70 Deutlich artikuliert von Paul. Nol., epist. 34, 4; Caes. Arel., serm. 25, 2.

71 Zu dieser Entwicklung im spätantiken Almosengeben vgl. auch Ramsay 1982, bes. 251-254. 
als im „Hirten des Hermas“ - in der „Heilsökonomie“, die zwischen Gott und Geber bestand, kein Handeln zugewiesen wurde. Man erwartete nicht, dass sie aktiv für ihre Wohltäter tätig wurden: Allein durch die Tatsache, dass sie Almosen in Empfang nahmen, fungierten sie als Transporteure des irdischen Reichtums, die einen „Schatz im Himmel“ anhäuften. ${ }^{72}$ Auch in den seltenen Fällen, in denen von einer Gebetsgabe des Armen die Rede ist, hat sie eine sekundäre, nur am Rande erwähnte Bedeutung: Entscheidend war die Vorstellung, dass Gott als Bürge für den Armen auftrat. ${ }^{73}$ Nur leicht variiert wurde dieselbe Haltung gegenüber den Armen in der Vorstellung wirksam, dass die Armen erst am Tag des Jüngsten Gerichts durch ihre Interzession und ihr Gebet tätig wurden. ${ }^{74}$ Auch hierin kommt klar zum Ausdruck, dass eine Gegengabe des Armen in der diesseitigen Welt, die in ähnlicher Weise wie ein Gabentausch zwischen Euergeten und Bürgern eine dauerhafte soziale Relation zwischen christlichen Euergeten und den Armen strukturiert hätte, keine Option war: Die besitzlosen Unterschichten, die in der Literatur der Spätantike in der Regel als eine gesichtslose, amorphe Masse ${ }^{75}$ ohne die Würde des Armen erscheinen, die für den „Hirten des Hermas“ charakteristisch ist, waren nicht in der Lage, an die Stelle der Bürger zu treten und eine neue Stadt zu bilden.

Diese Vorbehalte bedeuten nicht, dass es in der Spätantike keinerlei Ansatzpunkte für eine Form des christlichen Euergetismus, bei dem die Armen die Rolle der traditionellen Klienten übernahmen, gegeben hätte. Ein Angehöriger der Reichsaristokratie wie Paulinus von Nola, dessen Denken stark von traditionellen Patronagevorstellungen durchdrungen war, kleidete die Relation der reichen Geber zu den Armen in Bilder, die denen der Patrone zu ihren Klienten entsprachen. Als Pammachius, ein Angehöriger der römischen Senatsaristokratie, im Jahr 397 seine Frau Paulina bestatten und aus diesem Anlass ein Mahl für die Armen in der vatikanischen Petrusbasilika ausrichten ließ, partizipierten er und Paulina an den Dankgebeten der Armen, „von deren Jubel“, so Paulinus von Nola, „die Stadt widerhallte, als ihr eure Barmherzigkeit über den Bedürftigen ausströmen ließet, indem ihr sie nährtet

72 Beispiele bei de Vinne 1995, 98-100.

73 Vgl. Aug., in psalm. 36, 3, 6: Augustinus stellt zwar die Möglichkeit in Aussicht, den Armen zum Gebet $\mathrm{zu}$ verpflichten (sola in illo remanet benevolentia orandi pro te), doch kreisen seine Ausführungen um die Vorstellung, dass die Armenfürsorge eine erlaubte Form des Zinswuchers (feneratio) darstellt, der Aussicht auf Dividende verspricht, weil Gott für den Armen bürgt (si non tenes pauperem redditorem, sed ideoneum tenes fideiussorem [scil. Gott]). Auch hier vollzieht sich der Gabentausch mit Gott, der für den Armen bürgt; das Handeln des Armen ist zweitrangig.

74 Max. Taur., serm. 27, 1: in die enim iudicii pauperes tibi prosunt, amici filiique nibil prosunt. Caes. Arel., serm. 25, 1 lässt die misericordia für die Armen als personifizierte patrona beim Jüngsten Gericht auftreten (faciamus nobis illam patronam in hoc saeculo, ut nos ipsa liberet in futuro).

75 Brown 2002, $13 \mathrm{f}$. 
und kleidetet.“76 In einem anderen Zusammenhang bemühte Paulinus gegenüber einem nicht näher bezeichneten Adressaten ein ähnliches Bild von den Armen, die aus Dank für die erhaltenen Gaben ,,in allen Kirchen für dich beten, dir auf allen Straßen freudig danken und sich an jedem Ort zum Gedächtnis deines Namens erheben, indem sie Gott lobpreisen. “77

Dieser ,aristokratische Stil“ ${ }^{78}$ in dem Paulinus das Verhältnis des Gebers zu den Armen zeichnete, lieferte jedoch keine nachhaltigen Anstöße für einen christlichen Euergetismus. Exemplarisch deutlich wird dies, wenn man die Äußerungen des Paulinus mit den Reaktionen des Hieronymus auf Paulinas Tod vergleicht. In einem Trostschreiben an Pammachius preist Hieronymus diesen dafür, dass er nach Paulinas Tod das Leben eines Asketen gewählt

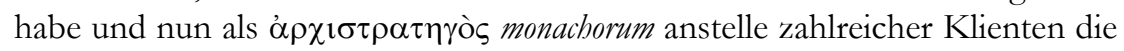
Armen um sich schare und in ihnen Christus selbst seine Fürsorge zuteil werden lasse. ${ }^{79}$ Von den Gebeten der Armen ist bei Hieronymus keine Rede. Pammachius erscheint bei ihm weniger als ein Patron der Armen, sondern vielmehr als ein Anführer mitten unter ihnen: Er demonstriert seine bumilitas, indem er selbst zum pauper wird. Der römische Aristokrat führte damit aus Sicht des Hieronymus zugleich die einzige Form von Armut vor, die ihren Träger qualifizierte und auf diese Weise zu einem Gabentausch befähigte, wie ihn der „Hirte des Hermas“ formuliert hatte: Den Armen, die „unter Lumpen und Schmutz von der Fleischeslust beherrscht werden“, billigte Hieronymus nicht zu, dass auf sie die biblische Aufforderung zutraf, sich mit dem Mammon Freunde zu schaffen, um von ihnen in die himmlischen Wohnungen aufgenommen $\mathrm{zu}$ werden. ${ }^{80}$ Dieses Privileg wurde nicht den ökonomisch Armen, sondern den pauperes spiritu zuteil, denjenigen also, die sich im Geiste asketischer Entsagung auf ihren Besitz verzichtet hatten. Die nackte Besitzlosigkeit hingegen war - nicht nur für Hieronymus - keine besondere Auszeichnung: Was zählte, waren Askese und freiwillige Armut. ${ }^{81}$

$76 \quad$ Paul. Nol., epist. 13, 14: quam bono tunc urbs nostra tumultu fremebat, cum tu misericordiae viscera reficiendis et operiendis pauperibus effundens pallida esurientium corpora reformares. Zum Gebet der Armen vgl. ebd: vobis enim ad iustitiam deputabatur conclamatio illa et conprecatio pauperum, qua per vestra munera benedicebatur deo. facili enim via ad aurem dei voces inopum diriguntur.

77 Paul. Nol., epist. 34, 10: in omnibus ecclesiis pro te rogant, in omnibus plateis tibi gratulantur, et in locis singulis ad commemorationem tui nominis eriguntur benedicentes dominum.

78 So der treffende Kommentar von Ramsey 1982, 248 (,aristocratic manner“).

79 Hier., epist. 66, 4f.

80 Hier., Vigil. 14: Salvator in evangelio loquebatur: , facite vobis amicos de mammona iniquitatis, qui vos recipiant in aeterna tabernacula.' nunquid isti pauperes, inter quorum pannos et illuviem corporis flagrans libido dominatur, possunt habere aeterna tabernacula, qui nec praesentia possident nec futura? Non enim simpliciter pauperes, sed pauperes spiritu beati appellantur, de quibus scriptum est: ,beatus qui intelligit super egenum et pauperem: in die mala liberabit eum dominus. "

81 Hieronymus hob mehrfach hervor, dass ökonomische Armut nicht in besonderer Weise qualifiziere: Hier., epist. 120, 1; ders., in Matth. 4, 25, 40: sed ex boc quod sequitur: quando fecistis uni de bis fratribus meis minimis, mibi fecistis; non mibi videtur generaliter dixisse de pauperibus, sed de bis qui 
Man mochte den ökonomisch Armen zwar Almosen geben und dadurch einen Schatz im Himmel anhäufen - doch nur mit den asketischen Armen ließ sich auf Erden ein Gabentausch zwischen Arm und Reich vollziehen, wie ihn Hermas formuliert hatte. ${ }^{82}$ Als Caesarius von Arles (469/470-542) das Gleichnis von Ulme und Weinstock aus dem „Hirten des Hermas“ erneut aufgriff, hatte sich der Charakter der Armut erheblich gewandelt. Aus dem ökonomisch Armen war ein pauper Christi geworden:

„Der Weinstock aber bezeichnet die Diener Gottes, die Äbte, die Mönche und die religiosen Kleriker, die sich Gott hingeben und beständig seiner Lehre obliegen, sie und alle anderen, die in ähnlicher Weise die Welt verachten und Gott Tag und Nacht dienen: Von ihrem Dienst glauben wir, dass er in der ewigen Seligkeit reiche Frucht bringen wird." $" 83$

Dort, wo die Memoria sich auch unter christlichen Vorzeichen nicht auf einen Gabentausch mit Gott beschränkte, sondern im Diesseits soziale Beziehungen zwischen Gebern und Armen begründete, waren es diese pauperes Christi, die ihn vollzogen. Damit verlagerte sich der memoriale Gabentausch auf Trägergruppen und auf Praktiken, die - im Unterschied zum euergetischen Gabentausch - ihren Ort nicht mehr im städtischen Raum hatten und nur noch in eingeschränktem Maße sozial erfahrbar waren. Um die Wende vom 5. zum 6. Jh., als Caesarius von Arles seine Deutung des Gleichnisses vom Weinstock und der Ulme vortrug, waren die wesentlichen Voraussetzungen für diesen Prozess, der dann im weiteren Verlauf des Frühmittelalters deutlichere Gestalt gewann, bereits gelegt worden. Mit dem Frauenkloster St. Jean in Arles schuf Caesarius das früheste historisch fassbare Beispiel für eine monastische Gemeinschaft in Gallien, die einen interzessorischen Gebetsdienst für ihren Gründer leistete. ${ }^{84}$ Obwohl das Kloster seinen Ort innerhalb der Stadt hatte, ${ }^{85}$ übertrug Caesarius diese

pauperes spiritu sunt, zu diesem asketischen Armutsverständnis vgl. dens., in Is. 58, 6f. (CC 73A, 666f.). Ähnlich urteilte Gregor I., dial. 1, 9: Die Armut ist für gute Seelen eine Wächterin der Demut, sie macht aber nicht per se gut; zur asketisch-monastischen im Unterschied zur ökonomischen Armut vgl. auch ebd. 4, 2.

82 Nicht hinreichend berücksichtigt von Finn 2006, 179-188, der von einer grundsätzlichen Aufwertung des Armen aufgrund der von ihm erwarteten Gegenleistung ausgeht, ohne zwischen ökonomischer und freiwilliger Armut zu differenzieren.

83 Caes. Arel., serm. 27, 1: vitis autem significat servos Dei, abbates, monachos vel clericos spiritales, in Deo vacantes, et doctrinae ingiter insistentes, et si qui sunt alii similes horum, qui contempto mundo Deo die noctuque deserviunt: quo servitio in aeterna beatitudine uberes fructus habere creduntur. Für die Bezeichnung als pauperes Christi vgl. den weiteren Verlauf von Caesarius' Ausführungen: hoc enim expedit fieri, ut, quomodo arbor ulmea extendit ramos suos, et erigit vel sustinet vitem, sic dives saeculi huius porrigat ramos suos, id est, ramos plenas fructibus agri sui, ut sustinet pauperes Christi.

84 In der Regel für sein Frauenkloster hob Caesarius die Aufgabe des Gebetsgedenkens an mehreren Stellen hervor; vgl. Caes. Arel., reg. virg. 1, 4; 72 (Gebet für Caesarius und die Äbtissinnen), 40, 2 (Gebet pro universo populo). Zum Zeugnis vgl. Muschiol 1994, $179 \mathrm{f}$.

85 Zur Lage des Klosters vgl. Février 1986 (a), 75, 81. 
Aufgabe einer Gemeinschaft, deren strenge Klausur und Abschließung von der Außenwelt ein besonders reines Gebetsgedenken gewährleistete. ${ }^{86}$ Der memoriale Gabentausch wurde damit von einer Gruppe vorgenommen, für die der Rückzug aus der Welt und den sie konstituierenden Sozialbeziehungen eine programmatische Bedeutung hatte: Er vollzog sich hinter den Mauern eines Klosters und in einer Weise, die für die städtische Gemeinschaft, der Caesarius als Bischof vorstand, weder sicht- noch erfahrbar war.

Ähnliches gilt auch für die Formen, unter denen die clerici religiosi, die für Caesarius neben den abbates und monachi als zweite Gruppe die pauperes Christi verkörperten, ihren Memorialdienst vornahmen. Von den mit der Entstehung der Votivmesse verbundenen Verschiebungen der in der Eucharistiefeier wirksamen memorialen Gabentauschbeziehungen ist bereits an anderer Stelle ausführlich die Rede gewesen: ${ }^{87}$ In dem Maße, in dem die priesterliche Darbringung des eucharistischen Opfers einen Gabentausch mit Gott akzentuierte, trat die soziale Semantik der Oblationen, die einen Tausch von Gabe und Gedenken auf der Ebene der feiernden Gemeinde bewirkt hatte, in den Hintergrund. Die Konsequenzen dieser Entwicklung lassen sich strukturell mit den monastischen Formen des Gebetsgedenkens vergleichen: Die Betonung der vertikalen Achse innerhalb des dreigliedrigen Schemas von Gabentauschbeziehungen führte zu einem Anstieg von Votivmessen, die in kleinem Teilnehmerkreis gefeiert wurden, und in denen die Gemeindebezogenheit der Oblation und die sozialen Aspekte des Gedenkens von nachrangiger Bedeutung waren. In ihren äußeren Formen wird diese Entwicklung zwar erst seit dem späteren 6. Jh. fassbar, als die Zunahme an Messfeiern zu einem Anstieg der Altäre in den Kirchen führte. Die frühesten Ansätze treten jedoch bereits seit der Mitte des 5. Jh. deutlich hervor. Mehrere gallische Konzilien legten seit dieser Zeit fest, dass die Oblationen von paenitentes, die vor ihrer Absolution und Wiedereingliederung in die Kirchengemeinschaft gestorben waren, dennoch zur Darbringung angenommen werden sollten: memoria eorum et orationibus et oblationibus commendetur. ${ }^{88}$ Die aus diesen kirchenrechtlichen Regelungen ersichtliche Sorge um das liturgische Gedenken für die Toten fand ihren Niederschlag in der Ausbildung eigener Votivmessen für die Verstorbenen, die seit dem frühen 6. Jh. neben den

\footnotetext{
86 Diese Verbindung zwischen klaustraler Einschließung, Reinheit und besonderer Wirksamkeit des Gebetsgedenkens hat Diem 2005, 154-202 überzeugend herausgearbeitet.

87 Vgl. zum folgenden o., S. 421-424.

88 Conc. Vas. (442), c. 2 (CC 148, 96): pro bis qui paenitentia accepta... sine communione inopinato nonnumquam transitu in agris aut itineribus praeveniuntur, oblationem recipiendam et horum funera ac deinceps memoriam ecclesiastico affectu prosequendam; ; ebenso Stat. eccl. ant. (ca. 475), c. 22 (CC 148, 170): paenitentes, qui attente leges paenitentiae exequnntur, si casu in itinere vel in mari mortui fuerint, ubi eis subveniri non potuit, memoria eorum et orationibus et oblationibus commendetur.
} 
Gemeindemessen, den missae publicae, in Gallien nachweisbar sind. ${ }^{89}$ Dass sich um die Wende vom 5. zum 6. Jh. das liturgische Totengedenken und die mit ihm verbundenen Oblationen für die Kleriker $\mathrm{zu}$ einem wesentlichen Wirtschafts- und Unterhaltsfaktor entwickelten, wird ferner daraus ersichtlich, dass zu Beginn des 6. Jh. ein Verteilungsmodus eingeführt wurde, der den Klerikern der Ortskirchen neben dem Bischof einen Anteil an den Messoblationen zusicherte: ${ }^{90}$ War noch wenige Jahrzehnte zuvor das Prinzip eingeschärft worden, dass sich der Klerus durch eigene Arbeit zu ernähren hatte, deuten diese Regelungen darauf hin, dass das Oblationswesen in der Zeit um 500 eine erhebliche Einnahmequelle für den Klerus darstellte. ${ }^{91}$

Sowohl für das monastische Gebetsgedenken als auch für die Votivmesse als Erscheinungsform der eucharistischen Memoria kann demnach die Wende vom 5. zum 6. Jh. als eine Scharnierzeit gelten, in der sich neue Formen einer christlichen Memorialkultur entwickelten. Ihnen gemeinsam ist, dass sie das fragmentierende Potential verdeutlichen, das eine jüdisch-christliche Konzeptualisierung von Erinnerung und Gedenken für sozial erfahrbare Handlungsbeziehungen in sich barg: Anders als im euergetischen Gabentausch war der Gebetsdienst von Mönchen und Klerikern eine memoriale Gegengabe, die für den Geber prinzipiell nicht als solche erfahrbar sein musste. Die Fragmentierungs- und Nuklearisierungstendenzen des städtischen Raums und der christlichen Sakraltopographie in der Spätantike sind zum Teil unmittelbare Konsequenzen dieser Entwicklung, die im weiteren Verlauf der frühmittelalterlichen Geschichte noch deutlicher hervortraten: Das in den Inseln städtischer Klöster angesiedelte Gebetsgedenken verlor im Zuge der irofränkischen Klostergründungen, die vorzugsweise in Gebieten ohne städtische Zivilisation vorgenommen wurden, die Bindung zur Stadt vollkommen; ${ }^{22}$ die Votivmesse erfuhr eine Steigerung in der ganz allein vom Zelebranten gefeierten missa solitaria und führte dazu, dass innerhalb der Kirchenräume einzelne liturgische Zentren und Altäre entstanden. Wichtiger als diese unmittelbaren Auswirkungen auf die städtische und sakrale Topographie war jedoch, dass die christliche Memorial-

89 Conc. Vas. (529), c. 3 (CC 148A, 79): in omnibus missis seu in matutinis, seu in quadragensimalibus seu in illis, quae pro defunctorum commemorationibus fiunt.

90 Für die städtische Bischofskirche und die Parochialgemeinden galten unterschiedliche Verteilungsschlüssel; vgl. Conc. Aurel. (511), c. 14 u. 15 (CC 148A, 9). Zu den Oblationsregelungen der gallischen Synodalgesetzgebung vgl. ausführlich Stutz ${ }^{21961,72-79 .}$

91 Stat. eccl. ant. (ca. 475), c. 29, 79 (CC 148, 171, 179). Angenendt 1983, 168f. deutet die Beteiligung der Kleriker an den Oblationen, die das Konzil von Orléans festlegte (vgl. die vorige Anm.), als Hinweis auf die gestiegene liturgische Verpflichtung der Kleriker.

92 Zu der mit Luxeuil einsetzenden Gründungswelle der irofränkischen Klöster im 7. Jh. (ca. 590690) vgl. Prinz 21988, 541f. Das gallische Mönchtum war bis dahin städtisch geprägt; eine gewisse Ausnahme bildeten die um 500 gegründeten Juraklöster, die als Vorläufer von Luxeuil gelten können. 
kultur auf grundlegend anderen Voraussetzungen beruhte als die antike Memorialkultur, in der das Gedenken eine rein soziale und innerweltlich begründete Gabe war. Wo die frühmittelalterliche Memoria eine sozial verbindende Wirkung entfaltete, wie beispielsweise in der Ausbildung von Gebetsbünden zwischen einzelnen Klöstern und Bischofskirchen, ${ }^{93}$ basierte sie auf spirituellen Formen der Gemeinschaftsstiftung, die diesen Handlungszusammenhang nicht als einen sozial erfahrbaren hervortreten ließen. Die neue Memorialkultur hatte nicht nur in räumlicher Hinsicht ihren Ort nicht mehr in der Stadt - und umgekehrt war die Stadt ohne Memoria nicht mehr dieselbe.

Die historischen Ausprägungen dieser Entwicklung systematisch auszuloten und den dadurch in Gang gesetzten Transformationsprozess in seinen unterschiedlichen regionalen Ausprägungen zu untersuchen, wäre das Thema für ein eigenes Buch und ist nicht mehr Aufgabe dieser Studie. Ihre strukturellen Beobachtungen bleiben davon jedoch unberührt. Das Ende der antiken Stadt lag wesentlich in den Voraussetzungen einer Religion begründet, die - bei aller Akkulturation durch die griechisch-römische Welt, in der sich die christlichen Gemeinden entwickelten - grundlegenden Prinzipien verhaftet blieb, die einem anderen kulturellen Kontext entstammten. Dazu zählte nicht nur eine karitative Armenfrömmigkeit, die den Bürger durch eine neue soziale Bezugsgruppe der Zuwendung von Gaben ersetzte. Vielmehr waren das Wechselspiel von Gabe und Gedenken und die dadurch begründeten euergetischen bzw. karitativen Handlungszusammenhänge fundamental voneinander verschieden. Die Dreigliedrigkeit des christlichen Gabentauschs, wie sie im „Hirten des Hermas“ formuliert wurde, schuf, in Verbindung mit der Ausdehnung der Handlungsbeziehungen über die Grenze des Todes hinweg, die Voraussetzungen dafür, dass die Achse der sozialen Handlungsbeziehungen zwischen dem Geber und dem Armen geschwächt wurde. Entscheidend war der Gabentausch, der sich zwischen Gott und den Menschen vollzog. Die sozialen Formen seiner Vermittlung waren demgegenüber sehr variabel: Eine Interzession der Armen konnte am Ende der Zeiten erfolgen oder sich dadurch, dass man Christus selbst im Armen gab oder ihn zum Bürgen machte, auf einen Gabentausch zwischen dem Geber und Gott reduzieren. Wo ein Gebetsgedenken der Armen im Diesseits erfolgte, waren es nicht die ökonomisch Armen, sondern die pauperes spiritu und pauperes Christi, die ihn übernahmen: Asketen, die sich aus dem saeculum zurückzogen, und Kleriker, durch deren Altardienst die Eucharistie ihren gemeinschaftsstiftenden Charakter verlor. Die spezifisch christliche Vorstellung von einem umfassenden, Lebende wie Tote umspannenden Handlungszusammenhang verstärkte diese Tendenz zur Schwächung sozial

$93 \quad$ Vgl. de Jong 1995, 647-651 u. o., S. 13. 
erfahrbarer Handlungsbeziehungen zusätzlich: Es war das Totengedenken, das eine der wesentlichen Antriebskräfte für die Ausbildung von Votivmessen und eine monastische Gebetsmemoria bildete. Der Memorialdienst erfüllte damit nicht mehr den Sinn, die sozialen Relationen innerhalb der Bürgerschaft und von Gruppen, die für das Sozialgefüge der römischen Stadt von Bedeutung waren, zu regulieren. Die neue Memorialkultur hatte keine Verbindung zur antiken Stadt, deren soziale Struktur und monumentales Erscheinungsbild auf einem euergetischen Gabentausch basierten, in dem das Wechselspiel von Gabe und Gedenken konsequent innerweltlich begründet war.

In struktureller Hinsicht lässt sich die spätantike Heiligenverehrung damit als Teilaspekt einer spezifisch christlichen Memorialkultur begreifen. Die Position, die der gedenkende Arme in dem dreigliedrigen Gabentauschmodell einnahm, war ein Strukturelement, das jedoch - abhängig von den sich wandelnden historischen Rahmenbedingungen - variabel besetzbar war: durch ökonomisch Arme ebenso wie durch Heilige, Asketen und Kleriker. Es handelt sich damit um eine Struktur, die im Lauf der antiken Entwicklung sehr unterschiedliche historische Ausprägungen erfuhr. Die Armenfrömmigkeit der frühchristlichen Gemeinden führte $\mathrm{zu}$ anderen sozialen Konsequenzen als die Heiligenverehrung, die sich seit dem 3. Jh. ausbildete, und als der Memorialdienst, den Asketen und Priester im Übergang von der Spätantike zum Mittelalter übernahmen. Die christliche Konzeptualisierung von Memoria ist dementsprechend nicht geeignet, aus sich heraus kulturellen Wandel zu erklären: Sie ist nur ein Element innerhalb eines komplexeren Zusammenhangs von Faktoren, in deren Zusammenspiel die konnektive Struktur einer Kultur, einer Gesellschaft oder eines Kollektivs begründet liegt. Dennoch ist unverkennbar, dass die jüdisch-christliche Tradition des Gedenkens eine inhärente Tendenz zur Schwächung von Sozialbeziehungen beinhaltete: In den Graffiti unter S. Sebastiano und der frühchristlichen Sepulkralepigraphik mit ihrer Aufforderung, die Heiligen und Toten möchten sich derer erinnern, die sich mit ihren Gaben an sie wandten, kündigte sich erstmals eine Vorstellung an, die langfristig das soziale Bezugssystem von Memoria grundlegend transformierte und in nuce die Voraussetzungen für eine Auflösung der traditionellen Beziehungen, die in der antiken Welt durch Memoria gestiftet wurden, in sich trug.

In den letzten Jahren ist von mediävistischer Seite verstärkt die Ansicht vorgetragen worden, die Memoria als eine soziale Gabe lasse sich als ein epochenübergreifendes Phänomen begreifen, das in der Antike ebenso wie im Mittelalter auf denselben strukturellen Voraussetzungen eines memorialen Gabentauschs beruht habe. Dabei werden wesentliche Eigentümlichkeiten der mittelalterlichen Memorialkultur bereits für die Antike vorausgesetzt. 
Otto Gerhard Oexle hat einen gemeinschaftsstiftenden Handlungs- und Kommunikationszusammenhang von Lebenden und Toten bereits für die römische Religion postuliert ${ }^{94}$ und Michael Borgolte dies zu der Vorstellung ausgeweitet, dass Stiftungen in der Antike ebenso wie im Mittelalter durch Gabentauschbeziehungen zwischen den toten Stiftern und den Lebenden, die zum Stiftergedenken verpflichtet wurden, begründet worden seien. ${ }^{95}$ Dass seit dem Frühmittelalter Klöster, Kirchen, Kleriker und Mönche die antike Stadt und die städtische Bevölkerung als Träger der Memoria ablösten, ist aus dieser Perspektive zwar durchaus eine Zäsur, jedoch kein Indiz für eine strukturelle Veränderung: Analog zu den antiken Städten hätten auch die kirchlichen Einrichtungen den Stiftern einen hohen Grad an institutioneller Sicherung und Verstetigung ihres Gedenkens geboten und seien daher zu bevorzugten Trägern der Erinnerung geworden. ${ }^{96}$

Dieser Ansatz, Erinnerung als eine soziale Gabe zu begreifen, operiert mit einem heuristisch fruchtbaren Modell, doch ist die Schlussfolgerung, Memoria sei als Strukturelement einer Kontinuität zwischen Antike und Mittelalter aufzufassen, wenig überzeugend: Erinnerung als memoriale Gegengabe liefert kein tertium comparationis für die antiken und mittelalterlichen Verhältnisse, da die Modalitäten dieses Gabentauschs sich grundlegend voneinander unterschieden. In der römischen Welt, in der das Wechselspiel von Gabe und Memoria auf innerweltlichen und sozial erfahrbaren Handlungszusammenhängen beruhte, strukturierte nicht der Tote, sondern der Lebende - auch dort, wo das Gedenken an ihn als Verstorbenen weiterlebte - die Handlungsbeziehungen, die durch Erinnerung begründet wurden. Mit der christlichen Konzeptualisierung der Memoria als Teil eines dreigliedrigen Gabentauschs und mit der Ausweitung der Handlungsbeziehungen in die jenseitige Welt und in die eschatologische Zeit lockerte sich dieser innerweltliche Bezug. Das Mittelalter liefert zwar zahlreiche Beispiele dafür, dass Memoria gemeinschaftsbildend wirken konnte, doch im Unterschied zur Antike fand sie - wie insbesondere das Abreißen der städtischen Kultur nachdrücklich zeigt - in der Regulierung sozial erfahrbarer Handlungsbeziehungen nicht ihre letzte Begründung und ihr Ziel.

$94 \quad$ Oexle 1983, 48-50; ders. 1984 (a). Zur Kritik an dieser Auffassung s. o., S. 62.

95 Borgolte 1988, 87, 91f.; ders. 1993, bes. 11f. Auch in diesem Punkt lassen sich die mittelalterlichen Verhältnisse nicht auf die Antike übertragen: Die spätantiken Stiftungen enthalten keine Hinweise auf die Vorstellung, dass der Tote durch seine Gegenwart die Dauer der Stiftung sicherte, sondern beruhen auf Rechtsvorstellungen, die sich bereits stark an das neuzeitliche Rechtskonzept der juristischen Person annähern (vgl. Barone Adesi 1993, bes. 261265).

$96 \quad$ Borgolte 1983 , bes. 248 f. 
Erinnerung begründete keine Kontinuität zwischen Antike und Mittelalter. Sie macht vielmehr grundlegende Brüche und Veränderungen deutlich, die einen Epochenwandel signalisieren. 